Article

\title{
Characteristics of the Bright Band Based on Quasi-Vertical Profiles of Polarimetric Observations from an S-Band Weather Radar Network
}

\author{
Jeong-Eun Lee, Sung-Hwa Jung * and Soohyun Kwon \\ Weather Radar Center, Korea Meteorological Administration, Seoul 07062, Korea; \\ wjddms4634@korea.kr (J.-E.L.); soohyun03@korea.kr (S.K.) \\ * Correspondence: shjung95@korea.kr; Tel.: +82-2-2181-0862
}

Received: 20 November 2020; Accepted: 7 December 2020; Published: 11 December 2020

\begin{abstract}
Bright band (BB) characteristics obtained via dual-polarization weather radars elucidate thermodynamic and microphysical processes within precipitation systems. This study identified BB using morphological features from quasi-vertical profiles (QVPs) of polarimetric observations, and their geometric, thermodynamic, and polarimetric characteristics were statistically examined using nine operational S-band weather radars in South Korea. For comparable analysis among weather radars in the network, the calibration biases in reflectivity $\left(\mathrm{Z}_{\mathrm{H}}\right)$ and differential reflectivity $\left(Z_{\mathrm{DR}}\right)$ were corrected based on self-consistency. The cross-correlation coefficient $\left(\rho_{\mathrm{HV}}\right)$ bias in the weak echo regions was corrected using the signal-to-noise ratio (SNR). First, we analyzed the heights of $B_{\text {PEAK }}$ derived from the $Z_{\mathrm{H}}$ as a function of season and compared the heights of $\mathrm{BB}_{\mathrm{PEAK}}$ derived from the $Z_{\mathrm{H}}, Z_{\mathrm{DR}}$, and $\rho_{\mathrm{HV}}$. The heights of $\mathrm{BB}_{\mathrm{PEAK}}$ were highest in the summer season when the surface temperature was high. However, they showed distinct differences depending on the location (e.g., latitude) within the radar network, even in the same season. The height where the size of melting particles was at a maximum $\left(\mathrm{BB}_{\mathrm{PEAK}}\right.$ from the $\left.\mathrm{Z}_{\mathrm{H}}\right)$ was above that where the oblateness of these particles maximized $\left(\mathrm{BB}_{\mathrm{PEAK}}\right.$ from $\left.\mathrm{Z}_{\mathrm{DR}}\right)$. The height at which the inhomogeneity of hydometeors was at maximum (BB $B_{\text {PEAK }}$ from the $\rho_{\mathrm{HV}}$ ) was also below that of $\mathrm{BB}_{\mathrm{PEAK}}$ from the $\mathrm{Z}_{\mathrm{H}}$. Second, $\mathrm{BB}$ thickness and relative position of $\mathrm{BB}_{\mathrm{PEAK}}$ were investigated to characterize the geometric structure of the $\mathrm{BBs}$. The $\mathrm{BB}$ thickness increased as the $\mathrm{Z}_{\mathrm{H}}$ at $\mathrm{BB}_{\mathrm{BO}}$ Tтом increased, which indicated that large snowflakes melt more slowly than small snowflakes. The geometrical structure of the BBs was asymmetric, since the melting particles spent more time forming the thin shell of meltwater around them, and they rapidly collapsed to form a raindrop at the final stage of melting. Third, the heights of $\mathrm{BB}_{\mathrm{TOP}}, \mathrm{BB}_{\mathrm{PEAK}}$, and $\mathrm{BB}_{\mathrm{BO}}$ ттом were compared with the zero-isotherm heights. The dry-temperature zero-isotherm heights were between $\mathrm{BB}_{\mathrm{TOP}}$ and $\mathrm{BB}_{\mathrm{BO}}$ TTOM, while the wet-bulb temperature zero-isotherm heights were close to the height of $\mathrm{BB}_{\text {PEAK}}$. Finally, we examined the polarimetric observations to understand the involved microphysical processes. The correlation among $\mathrm{Z}_{\mathrm{H}}$ at $\mathrm{BB}_{\mathrm{TOP}}, \mathrm{BB}_{\mathrm{PEAK}}$, and $\mathrm{BB}_{\mathrm{BOTTOM}}$ was high $(>0.94)$, and the $\mathrm{Z}_{\mathrm{DR}}$ at $\mathrm{BB}_{\mathrm{BOTTOM}}$ was high when the $\mathrm{BB}^{\prime}$ s intensity was strong. This proved that the size and concentration of snowflakes above the $\mathrm{BB}$ influence the size and concentration of raindrops below the $\mathrm{BB}$. There was no depression in the $\rho_{\mathrm{HV}}$ for a weak BB. Finally, the mean profile of the $Z_{\mathrm{H}}$ and $\mathrm{Z}_{\mathrm{DR}}$ depended on the $\mathrm{Z}_{\mathrm{H}}$ at $\mathrm{BB}_{\mathrm{BOTTOM}}$. In conclusion, the growth process of snowflakes above the $\mathrm{BB}$ controls polarimetric observations of $\mathrm{BB}$.
\end{abstract}

Keywords: quasi-vertical profile; S-band dual-polarization radar; bright band; melting layer; microphysical process 


\section{Introduction}

When falling snowflakes pass through the zero-isotherm layers into the warmer air, they melt and collapse to form raindrops, causing an increase in radar reflectivity (known as the bright band, hereafter $\mathrm{BB})$. The reflectivity $\left(\mathrm{Z}_{\mathrm{H}}\right)$ increases owing to the increase in the dielectric constant. Afterwards, the $Z_{\mathrm{H}}$ decreases upon the formation of raindrops, owing to the decrease in the size and number concentration of snowflakes caused by the increase in fall velocity $[1,2]$. The overestimation in $Z_{H}$ causes a significant error in radar rainfall estimates under the $\mathrm{BB}$ region. The identification of $\mathrm{BB}$ and correction of related errors are necessary for accurate estimations of precipitation [3-5]. The study of the vertical structure of the precipitation system associated with the melting layer and its characteristic analysis using remote sensing instruments is essential to understand cloud physics and rain microphysics. Weather radar can provide crucial information on melting layers with high spatiotemporal resolution. Therefore, detection and characterization of the BB using weather radar is one of the primary keys for understanding the microphysical processes related to the vertical structure of precipitation.

Most single-polarimetric techniques have identified the BB (i.e., peak, top, and bottom) based on a geometric feature from the vertical profile of $Z_{H}$ (VPR) [1,6-10]. The gradient of VPR has been commonly used to define the boundary of BB. Klaassen [11] and White et al. [12] used the change in radial velocity when snowflakes turn into raindrops as they pass through the melting layer to identify the BB. Dual-polarization radar can provide information on the size, shape, and phase of hydrometeors, resulting in improved BB detection [13-17]. Ryzhkov and Zrnić [13] showed that polarimetric signatures pronounce the presence of BB. Brandes and Ikeda [14] identified BB by matching observed and modelled profiles of polarimetric observations. Giangrande et al. [16] proposed thresholds for $\mathrm{Z}_{\mathrm{H}}$, the differential reflectivity $\left(\mathrm{Z}_{\mathrm{DR}}\right)$, and the cross-correlation coefficient $\left(\rho_{\mathrm{HV}}\right)$ to detect top and bottom boundaries of BB in an operational environment. Boodoo et al. [18] modified the technique developed by Giangrande et al. [16] for a C-band radar in southern Ontario, Canada. The top of the $\mathrm{BB}$ effectively matched the $0{ }^{\circ} \mathrm{C}$ wet-bulb temperature layer. Illingworth and Thompson [19] showed that the linear depolarization ratio (LDR) was valuable for identifying BB and correcting an increase in $Z_{H}$ due to BB. Hall et al. (2015) developed a fuzzy logic-based BB detection technique using $\mathrm{Z}_{\mathrm{H}}, \mathrm{Z}_{\mathrm{DR}}, \rho_{\mathrm{HV}}$, and LDR.

Fabry and Zawadzki [1] analyzed the vertical structure of $B B$ revealed by $X$-band vertically pointing radar and wind profiler. The intensity of $\mathrm{BB}$ depends on variations in the refractive index, shape, and density of hydrometeors. Zawadzki [20] developed a BB model that showed that dense particles reduce the difference in $\mathrm{Z}_{\mathrm{H}}$ at the peak height of the $\mathrm{BB}$ and in the rain region. Wolfensberger et al. [21] analyzed the characteristics of BB using the range-height indicator (RHI) scan mode at various climatic regions (i.e., South of France; Swiss Alps and plateau; and Iowa, USA). The distribution of polarimetric observations within the BB was similar regardless of the season and climatic regions. They also showed that the thickness of $B B$ is highly related to the presence of rimed particles, the fall velocity of the hydrometeors, and BB intensity.

Recently, quasi-vertical profiles (QVPs) of polarimetric observations (described in more detail in Section 3) were used to investigate the vertical structure and microphysical processes of the precipitation system [22-25]. Kumjian et al. [22] first used QVP to detect refreezing signals of precipitation during winter storms. According to Ryzhkov et al. [24], QVP is a useful tool for the examination of microphysical processes resulting in precipitation on the surface and aids in the determination of the growth process of snowflakes. Kumjian and Lombardo [23] analyzed the microphysical and dynamic characteristics of winter snowstorms. They found that an increase in differential reflectivity $\left(\mathrm{Z}_{\mathrm{DR}}\right)$ represented the initial stage of planar crystal growth, and an increase in the specific differential phase $\left(\mathrm{K}_{\mathrm{DP}}\right)$ indicated the high number concentrations of planar crystals. The supersaturation caused by the ascent boosts the depositional growth and raises the potential of an increase in $K_{D P}$. Trömel et al. [26] showed the potential of ground precipitation nowcasting by identifying microphysical processes of stratiform snowfall storms. The $\mathrm{K}_{\mathrm{DP}}$ increase in the dendritic growth layer (DGL, between -10 and $-20{ }^{\circ} \mathrm{C}$ ) exhibited a very high correlation with rainfall on the ground after half an hour. Griffin et al. [27] detected 
BB and analyzed the microphysical processes associated with BB and DGL for stratiform precipitation in winter. Using the QVPs of polarimetric observations, they identified a weak $B B\left(Z_{H}\right.$ of $\left.<20 \mathrm{dBZ}\right)$ whose detection failed when using the vertical profile of $Z_{H}$ only. They also compared polarimetric observations above, within, and below the BB using QVPs for the first time at the $S$ band.

In this study, we identified BB using the QVPs of polarimetric observations obtained from nine S-band dual-polarization radars operated by the Korea Meteorological Administration (KMA). For the analysis of BB characteristics, geometric features (including heights of the BB peak, top, and bottom at QVPs) were analyzed statistically, and then compared to the height of the $0{ }^{\circ} \mathrm{C}$ isotherm. Finally, the characteristics of polarimetric observations at the top, peak, and bottom of the BB were examined to determine the microphysical processes related to the BB.

\section{Materials and Methods}

\subsection{Materials and Data}

The KMA has operated a nationwide weather radar network composed of 10 S-band weather radars since 2008 and sequentially replaced all radars of the network with S-band dual-polarization radars during the period from 2014 to 2019. Figure 1 shows the deployment of the KMA S-band dual-polarization weather radar. The replacement began with the BRI radar at the northwestern island in 2014 and ended with the GNG radar at the northeastern coast in November 2019. We used a total of nine weather radars, except for the GNG radar, to analyze the characteristics of the BB from March to November 2019. Table 1 shows the volumetric scan strategies of the weather radar in the KMA network. All strategies consisted of nine elevation angles, including a wind profiling mode of $15^{\circ}$ and were repeated every $5 \mathrm{~min}$. Notably, several radars (i.e., KWK, MYN, and PSN) installed at a relatively high altitude ( $>600 \mathrm{~m}$ mean sea level (MSL)) employed a negative (-) elevation as the lowest elevation angle. The elevation angles for the lowest scan were determined based on a radar beam blockage simulation for standard beam propagation using the digital elevation model with a horizontal resolution of 1 arc second. The radar transmits a long pulse with a width of $2 \mu \mathrm{s}$ at low elevation angles (less than $3^{\circ}$ ) to enhance the detectability of weak low-level echoes, such as winter snowstorms, whereas a short pulse of $1 \mu$ s pulse width is used at higher elevation angles $\left(>3^{\circ}\right)$ to increase the Nyquist velocity using high pulse repetition frequency (PRF). This configuration of the pulse length is based on the sensitivity test by Lee et al. [28]. They found that a longer pulse length (i.e., $2 \mu \mathrm{s}$ ) improved radar sensitivity and increased the spatial extent of the precipitation echo for radar reflectivity and all dual-polarimetric observations. The azimuthal and radial resolutions were $1.0^{\circ}$ and $250 \mathrm{~m}$, regardless of the elevation angle. The BB was identified using QVPs of polarimetric observations at the highest elevation angle of $15.0^{\circ}$.

To analyze the thermodynamic characteristics of $\mathrm{BB}$, three-dimensional dry-bulb temperature $(\mathrm{T})$, dew point temperature $\left(T_{d}\right)$ and wet-bulb temperature $\left(T_{w}\right)$ data from three-dimensional atmospheric fields ( $T, T_{d}$, and pressure) were generated by multi-quadric interpolation using observational data and very short-range data assimilation and prediction systems (VDAPS) [29] were used every $5 \mathrm{~min}$. The horizontal resolution of three-dimensional atmospheric field data was $4 \mathrm{~km}$, and the vertical resolution was $100 \mathrm{~m}$ at altitudes of $0-2 \mathrm{~km}$ and $200 \mathrm{~m}$ at altitudes of $2-10 \mathrm{~km}$. The three-dimensional data consisted of $60 \times 257 \times 257(10 \mathrm{~km} \times 1024 \mathrm{~km} \times 1024 \mathrm{~km})$ grids. The temperature data was interpolated to the same vertical resolution of the QVPs (20 m). 


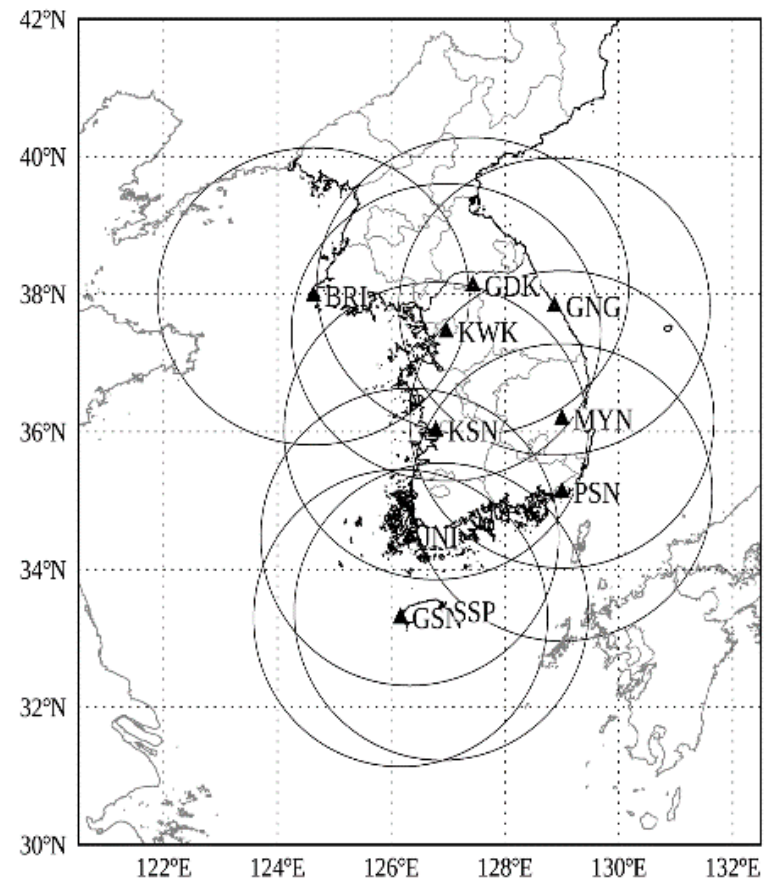

Figure 1. Deployment of the Korea Meteorological Administration (KMA) S-band dual-polarization weather radar network. The 10 circles indicate the $240 \mathrm{~km}$ radius coverage of the radar.

Table 1. Scan strategy of KMA operational S-band dual-polarization radars.

\begin{tabular}{lccccccccc}
\hline Radar & \multicolumn{8}{c}{ Elevation Angle $\left(^{\circ}\right)$} \\
\hline GDK & -0.40 & 0.01 & 0.31 & 0.80 & 1.41 & 2.50 & 4.20 & 7.11 & 15.01 \\
BRI & 0.10 & 0.42 & 0.81 & 1.41 & 2.20 & 3.41 & 5.10 & 7.61 & 15.01 \\
KWK & -0.19 & 0.00 & 0.30 & 0.81 & 1.50 & 2.60 & 4.40 & 7.30 & 15.01 \\
MYN & -0.80 & -0.39 & 0.01 & 0.41 & 0.91 & 1.91 & 3.60 & 7.00 & 15.01 \\
KSN & 0.00 & 0.30 & 0.70 & 1.30 & 2.10 & 3.21 & 5.00 & 7.61 & 15.01 \\
PSN & -0.09 & 0.20 & 0.60 & 1.10 & 1.81 & 3.00 & 4.71 & 7.40 & 15.01 \\
JNI & -0.09 & 0.20 & 0.60 & 1.10 & 1.81 & 3.00 & 4.71 & 7.42 & 15.02 \\
SSP & 0.20 & 0.50 & 1.01 & 1.60 & 2.41 & 3.50 & 5.20 & 7.60 & 15.00 \\
GSN & 0.20 & 0.50 & 1.01 & 1.60 & 2.41 & 3.50 & 5.20 & 7.60 & 15.01 \\
\hline
\end{tabular}

\subsection{Methodology}

\subsubsection{Construction of the QVPs}

The QVPs were obtained by azimuthal averaging individual polarimetric observations at each range gate and for the highest elevation angle $\left(15^{\circ}\right)$. According to Ryzhkov et al. [24], the QVP at an elevation angle between 10 and $20^{\circ}$ can reduce horizontal inhomogeneity. The QVP provides a stable vertical structure of the precipitation system for the $\mathrm{BB}$ identification, where $\mathrm{Z}_{\mathrm{H}}$ and $\mathrm{Z}_{\mathrm{DR}}$ increase and $\rho_{\text {HV }}$ decreases.

Two kinds of corrections were required for all KMA radars before constructing the QVPs of polarimetric observations as follows: (1) the calibration biases in the power-based polarimetric measurements (i.e., $Z_{\mathrm{H}}$ and $Z_{\mathrm{DR}}$ ) and (2) the correction of $\rho_{\mathrm{HV}}$ in the low SNR area. First, the calibration biases in $Z_{\mathrm{H}}$ and $\mathrm{Z}_{\mathrm{DR}}$ lead to an unsuitable identification of the $\mathrm{BB}$, and the different calibration biases among radars within the network resulted in a misunderstanding of the spatial and temporal statistics of BB. In this study, the $Z_{H}$ bias was corrected based on the self-consistency principle between $Z_{H}$ and differential phase $\left(\Phi_{\mathrm{DP}}\right)[30,31]$. The $Z_{\mathrm{DR}}$ bias was calibrated by comparing the empirical relationship between $Z_{H}$ and $Z_{D R}$ obtained from the drop size distribution of a two-dimensional video disdrometer 
(2DVD) to the $\mathrm{Z}_{\mathrm{H}}-\mathrm{Z}_{\mathrm{DR}}$ distribution of polarimetric measurements. Kwon et al. [31] described these two procedures in detail.

The noise caused by a radar receiver, waveguide, and antenna affects the quality of the polarimetric observations, even if the radar is properly calibrated [32]. The $\rho_{\mathrm{HV}}$ is biased in the low signal-to-noise ratio (SNR) areas. Meteorological echoes with a $\rho_{\mathrm{HV}}$ less than 0.98 are observed due to the bias related to the noise. The $\rho_{\mathrm{HV}}$ was corrected using the SNR as follows:

$$
\rho_{\mathrm{HV}}=\rho_{\mathrm{HV}}{ }^{(\mathrm{m})}(1+1 / \mathrm{snr})
$$

where $\rho_{\mathrm{HV}}{ }^{(\mathrm{m})}$ and $\rho_{\mathrm{HV}}$ are the measured and corrected $\rho_{\mathrm{HV}}$, respectively. The $\operatorname{snr}\left(=10^{0.1 S \mathrm{NR}(\mathrm{dB})}\right)$ is the SNR in linear units.

Radar observations included non-meteorological echoes. The regions with $\rho_{\mathrm{HV}}<0.7$, or with $\mathrm{SNR}<10 \mathrm{~dB}$, were removed to avoid contamination by non-meteorological echoes. The QVPs of polarimetric observations were constructed by obtaining the azimuthal average of $Z_{\mathrm{H}}, Z_{\mathrm{DR}}$, and $\rho_{\mathrm{HV}}$. As the radar beam broadens, the QVP resolution is reduced at high altitudes. In this study, QVPs were converted to high resolution by interpolating them to a vertical resolution of $20 \mathrm{~m}$. The QVPs of $Z_{\mathrm{H}}$, $Z_{\mathrm{DR}}$, and $\rho_{\mathrm{HV}}$ were used to analyze the characteristics of polarimetric observations at the top, peak, and bottom of the BB.

\subsubsection{Detection of the Bright Band (BB)}

Most $B B$ detection algorithms apply the first and second derivatives of $Z_{H}\left(d Z / d h\right.$ and $\left.d^{2} Z / d^{2}\right)$. However, local variations of $Z_{\mathrm{H}}$ can make the detection of the boundary of the BB challenging. A sharp curvature of $Z_{\mathrm{H}}$ is required for the detection of the top and bottom of the BB. The coordinate rotation method developed by Rico-Ramire and Cluckie [9] was used to detect the boundaries of the BB. This method is simple and has the advantage of reliably detecting the $\mathrm{BB}$ signature,.The $\mathrm{Z}_{\mathrm{H}}$ and $Z_{\mathrm{DR}}$ increase due to the increase in the hydrometeor dielectric constants and densities, and the $\rho_{\mathrm{HV}}$ decreases due to the diversity of the hydrometeor shapes, orientations, and densities. Before applying the coordinate rotation method, the $\rho_{\mathrm{HV}}$ was normalized to a value ranging between 0 and 100 , and then converted to a new variable (new $\rho_{\mathrm{HV}}=100-100^{*} \rho_{\mathrm{HV}}$ ), which increased in the BB as a result of this conversion.

The procedures for BB detection using the QVPs of the $\mathrm{Z}_{\mathrm{H}}, \mathrm{Z}_{\mathrm{DR}}$, and new $\rho_{\mathrm{HV}}$ were divided into the following two steps: (1) detection of the peak of the $\mathrm{BB}\left(\mathrm{BB}_{\mathrm{PEAK}}\right)$ and (2) detection of the top and bottom of the $\mathrm{BB}\left(\mathrm{BB}_{\mathrm{TOP}}\right.$ and $\left.\mathrm{BB}_{\mathrm{BOTTOM}}\right)$ using the coordinate rotation method. $\mathrm{BB}_{\text {PEAK }}$ was identified by calculating the first derivative of polarimetric observations. The first derivative was calculated from the difference in the polarimetric observations at a height of $60 \mathrm{~m}$ above and below a given height. $\mathrm{BB}_{\text {PEAK }}$ was obtained from the maximum polarimetric observations $\left(\mathrm{Z}_{\mathrm{H}}, \mathrm{Z}_{\mathrm{DR}}\right.$, and new $\left.\rho_{\mathrm{HV}}\right)$ within a height of $400 \mathrm{~m}$ above and below the height at which the first gradient was at maximum. The $\mathrm{Z}_{\mathrm{H}}, \mathrm{Z}_{\mathrm{DR}}$, and new $\rho_{\mathrm{HV}}$ at $\mathrm{BB} \mathrm{PEAK}_{\mathrm{P}}$ should be greater than $0.0 \mathrm{dBZ}, 0.0 \mathrm{~dB}$, and $2(=0.98)$, respectively. In this study, we briefly describe the coordinate rotation method. Figure 2 shows a diagram of the procedures for detecting $\mathrm{BB}_{\mathrm{TOP}}$ and $\mathrm{BB}_{\mathrm{BOTTOM}}$ from the QVP of the $\mathrm{Z}_{\mathrm{H}}$. First, the QVP was separated by the upper and lower parts of $\mathrm{BB}_{\mathrm{PEAK}}$ relative to the line connecting $\mathrm{BB}_{\mathrm{PEAK}}$ and $\mathrm{Z}^{\prime}$ lower, upper. The original coordinate was rotated $90^{\circ}$ in the clockwise (counterclockwise) direction to obtain the new coordinate with $\mathrm{h}^{\prime}$ upper $-\mathrm{Z}^{\prime}$ upper $\left(\mathrm{h}^{\prime}{ }_{\text {lower }}-\mathrm{Z}^{\prime}\right.$ lower $)$. Then, the height of $1200 \mathrm{~m}(800 \mathrm{~m})$ above (below) BB PEAK was selected to set the rotation angle $\varnothing$. The coordinate was again rotated $\varnothing$ degrees in the clockwise (counterclockwise) direction, and $\mathrm{h}^{\prime \prime}$ upper ( $\mathrm{h}^{\prime \prime}$ lower $)$ and $\mathrm{Z}^{\prime \prime}$ upper $\left(\mathrm{Z}^{\prime \prime}{ }_{\text {lower }}\right)$ are the $x$-axis and $y$-axis in the final coordinate. The maximum value in the final coordinate was defined as BВ

Figure 3 shows the time series of the QVPs of the $Z_{\mathrm{H}}$ (top), $Z_{\mathrm{DR}}$ (middle), and $\rho_{\mathrm{HV}}$ (bottom), and the heights of $\mathrm{BB}_{\mathrm{TOP}}$ (blue), $\mathrm{BB}_{\text {PEAK }}$ (black), and $\mathrm{BB}_{\mathrm{BOTTOM}}$ (red) at an elevation angle of $15^{\circ}$ for the BRI radar from 000 KST of 6 September 2019 to 1800 KST of 7 September 2019. In Figure 3a,c,e, the black solid line indicates BB height and the black dotted lines indicate $\mathrm{T}$ with a $5{ }^{\circ} \mathrm{C}$ interval 
(ranging from -30 to $20^{\circ} \mathrm{C}$ ). $\mathrm{BB}_{\mathrm{PEAK}}$ is located at the $\mathrm{Z}_{\mathrm{H}}$ maxima, $\mathrm{Z}_{\mathrm{DR}}$ maxima, and $\rho_{\mathrm{HV}}$ minima. $\mathrm{BB}_{\mathrm{TOP}}$ and $\mathrm{BB}_{\mathrm{BOTTOM}}$ are within a height of $500 \mathrm{~m}$ above and below $\mathrm{BB}_{\text {PEAK}}$. In Figure $3 \mathrm{~b}, \mathrm{~d}$, $\mathrm{f}$, the solid and dashed lines indicate the heights where $\mathrm{T}$ is $0{ }^{\circ} \mathrm{C}$ and $\mathrm{T}_{\mathrm{w}}$ is $0{ }^{\circ} \mathrm{C}$, respectively. The height of $\mathrm{BB}_{\mathrm{TOP}}$ is closer to the zero-isotherm layer $\left(\mathrm{T}=0^{\circ} \mathrm{C}\right)$ than that of $\mathrm{BB}_{\mathrm{PEAK}}$ and $\mathrm{BB}_{\mathrm{BOTTOM}}$.
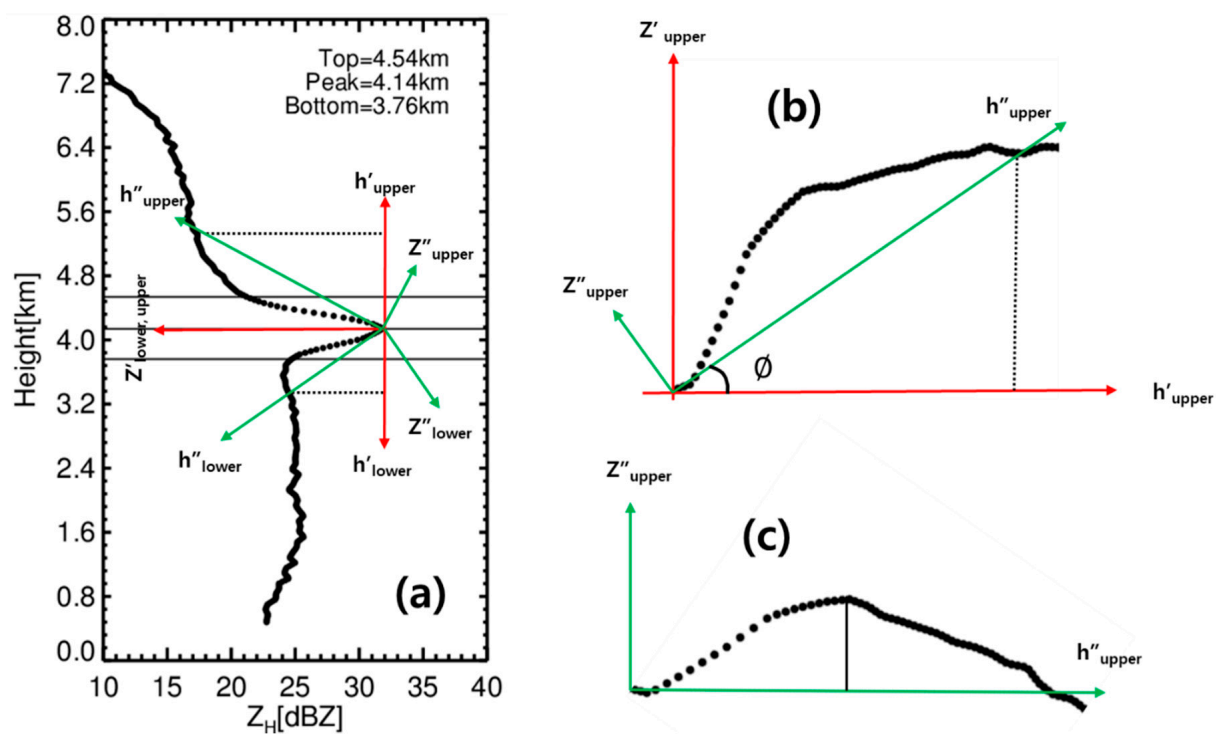

Figure 2. Quasi-vertical profile (QVP) of the $\mathrm{Z}_{\mathrm{H}}$ and the parameters defined for rotating coordinates. (a) Original coordinate; (b) New coordinate after $90^{\circ}$ rotation; (c) Final coordinate after $\varnothing$ degree rotation. The thin lines indicate the top, peak, and bottom of the bright band (BB) derived from the QVP of the $\mathrm{Z}_{\mathrm{H}}$.
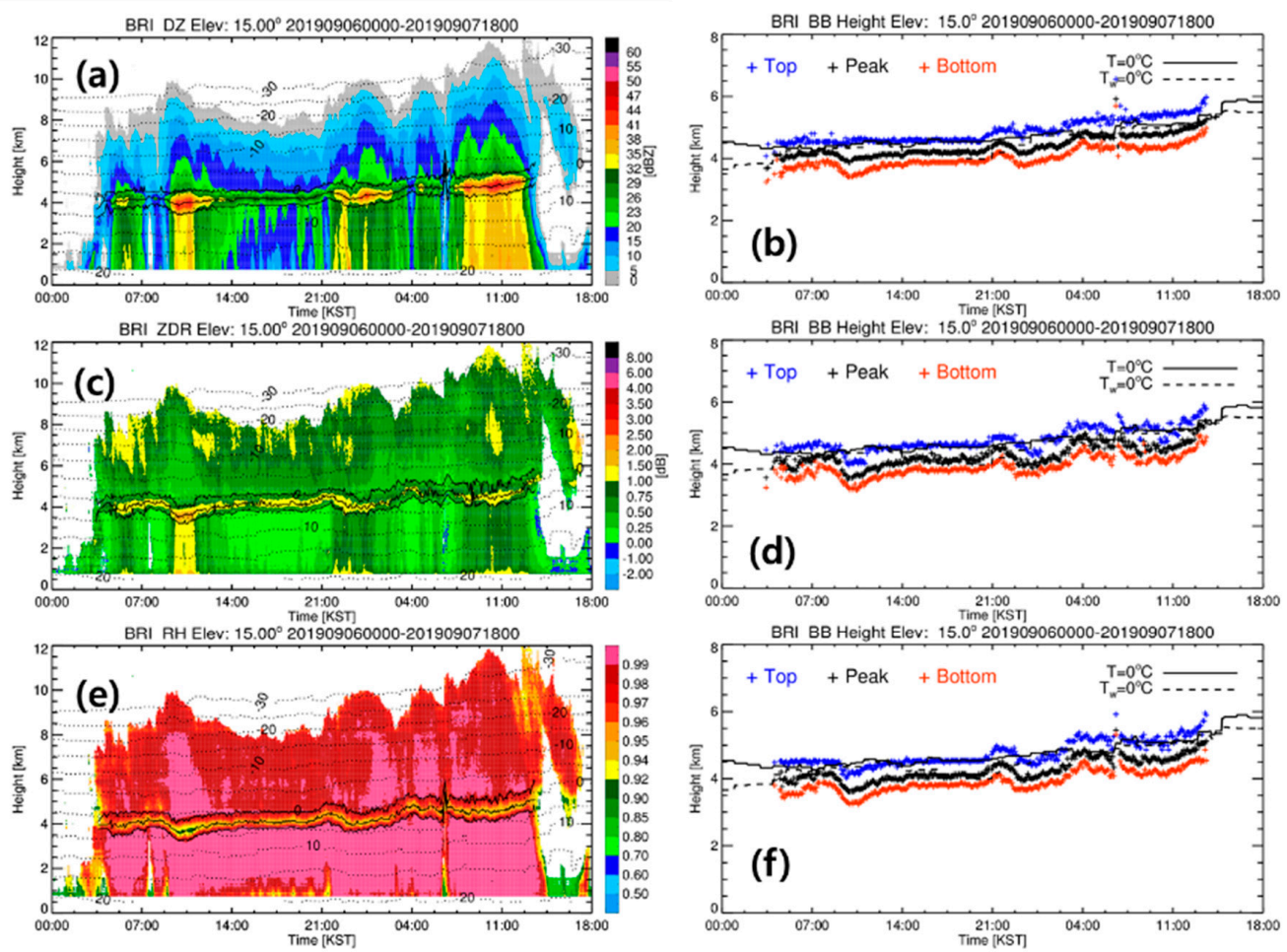

Figure 3. Time series of quasi-vertical profiles (QVPs) of the (a) $Z_{\mathrm{H}},(\mathbf{c}) \mathrm{Z}_{\mathrm{DR}}$, and (e) $\rho_{\mathrm{HV}}$ and the height of the top (blue), peak (black), and bottom (red) of the BB from the (b) $Z_{\mathrm{H}},(\mathbf{d}) \mathrm{Z}_{\mathrm{DR}}$, and (f) $\rho_{\mathrm{HV}}$ at elevation angles of $15.0^{\circ}$ of the BRI radar from 0000 KST of 6 September 2019 to 1800 KST of 7 September 2019. The solid and dashed lines indicate the heights where $\mathrm{T}$ is $0{ }^{\circ} \mathrm{C}$ and $\mathrm{T}_{\mathrm{W}}$ is $0{ }^{\circ} \mathrm{C}$, respectively. 


\subsubsection{Variables for Characterizing the BB}

The definitions of the feature parameters used to characterize the BB are presented in Table 2. These parameters are related to the geometric, thermodynamic, and polarimetric properties of the $\mathrm{BB}$. The heights of the $\mathrm{BB}\left(\mathrm{BB}_{\mathrm{TOP}}, \mathrm{BB}_{\mathrm{PEAK}}\right.$, and $\left.\mathrm{BB}_{\mathrm{BOTTOM}}\right)$ obtained by each polarimetric observation are $\mathrm{H}\left(Z_{\mathrm{H}}\right.$ Top $), \mathrm{H}\left(\mathrm{Z}_{\mathrm{H}}\right.$ Peak $), \mathrm{H}\left(\mathrm{Z}_{\mathrm{H}}\right.$ Bottom $), \mathrm{H}\left(\mathrm{Z}_{\mathrm{DR}}\right.$ Top $), \mathrm{H}\left(\mathrm{Z}_{\mathrm{DR}}\right.$ Peak $), \mathrm{H}\left(\mathrm{Z}_{\mathrm{DR}}\right.$ Bottom $), \mathrm{H}\left(\rho_{\mathrm{HV}}\right.$ Top), $\mathrm{H}\left(\rho_{\mathrm{HV}}\right.$ Peak $)$, and $\mathrm{H}\left(\rho_{\mathrm{HV}}\right.$ Bottom $) . \mathrm{H}\left(\mathrm{T}=0{ }^{\circ} \mathrm{C}\right), \mathrm{H}\left(\mathrm{T}_{\mathrm{d}}=0{ }^{\circ} \mathrm{C}\right)$, and $\mathrm{H}\left(\mathrm{T}_{\mathrm{w}}=0{ }^{\circ} \mathrm{C}\right)$ are the heights where $\mathrm{T}, \mathrm{T}_{\mathrm{d}}$, and $\mathrm{T}_{\mathrm{w}}$ are $0^{\circ} \mathrm{C} . \mathrm{Z}_{\mathrm{H}}$ Top, $\mathrm{Z}_{\mathrm{H}}$ Peak, $\mathrm{Z}_{\mathrm{H}}$ Bottom, $\mathrm{Z}_{\mathrm{DR}}$ Top, $\mathrm{Z}_{\mathrm{DR}}$ Peak, $\mathrm{Z}_{\mathrm{DR}}$ Bottom, $\rho_{\mathrm{HV}}$ Top, $\rho_{\mathrm{HV}}$ Peak, and $\rho_{\mathrm{HV}}$ Bottom, which are the polarimetric observations at the heights of $\mathrm{BB}_{\mathrm{TOP}}, \mathrm{BB}_{\mathrm{PEAK}}$, and $\mathrm{BB}_{\mathrm{BOTTOM}}$ were defined to analyze polarimetric characteristics in the $\mathrm{BB}$.

Table 2. Definitions of feature parameters for characterizing the BB.

\begin{tabular}{|c|c|}
\hline Feature Parameters & Definition \\
\hline $\mathrm{H}\left(\mathrm{Z}_{\mathrm{H}} \mathrm{Top}\right)$ & Height of $\mathrm{BB}_{\mathrm{TOP}}$ identified by QVP of $\mathrm{Z}_{\mathrm{H}}$ \\
\hline $\mathrm{H}\left(\mathrm{Z}_{\mathrm{H}}\right.$ Peak $)$ & Height of $B_{P E A K}$ identified by QVP of $Z_{H}$ \\
\hline $\mathrm{H}\left(\mathrm{Z}_{\mathrm{H}}\right.$ Bottom $)$ & Height of $\mathrm{BB}_{\text {ВОтОМ }}$ identified by QVP of $\mathrm{Z}_{\mathrm{H}}$ \\
\hline $\mathrm{H}\left(\mathrm{Z}_{\mathrm{DR}}\right.$ Top $)$ & Height of $\mathrm{BB}_{\mathrm{TOP}}$ identified by QVP of $\mathrm{Z}_{\mathrm{DR}}$ \\
\hline $\mathrm{H}\left(\mathrm{Z}_{\mathrm{DR}}\right.$ Peak $)$ & Height of $\mathrm{BB}_{\mathrm{PEAK}}$ identified by QVP of $\mathrm{Z}_{\mathrm{DR}}$ \\
\hline $\mathrm{H}\left(\mathrm{Z}_{\mathrm{DR}}\right.$ Bottom $)$ & Height of $\mathrm{BB}_{\mathrm{BOTTOM}}$ identified by QVP of $\mathrm{Z}_{\mathrm{DR}}$ \\
\hline $\mathrm{H}\left(\rho_{\mathrm{HV}} \mathrm{Top}\right)$ & Height of $\mathrm{BB}_{\mathrm{TOP}}$ identified by QVP of $\rho_{\mathrm{HV}}$ \\
\hline $\mathrm{H}\left(\rho_{\mathrm{HV}}\right.$ Peak $)$ & Height of $\mathrm{BB}_{\mathrm{PEAK}}$ identified by QVP of $\rho_{\mathrm{HV}}$ \\
\hline $\mathrm{H}\left(\rho_{\mathrm{HV}}\right.$ Bottom $)$ & 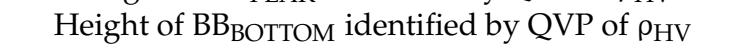 \\
\hline $\mathrm{H}\left(\mathrm{T}=0^{\circ} \mathrm{C}\right)$ & Height where $\mathrm{T}$ is $0^{\circ}$ \\
\hline $\mathrm{H}\left(\mathrm{T}_{\mathrm{d}}=0{ }^{\circ} \mathrm{C}\right)$ & Height where $T_{d}$ is $0^{\circ}$ \\
\hline $\mathrm{H}\left(\mathrm{T}_{\mathrm{W}}=0{ }^{\circ} \mathrm{C}\right)$ & Height where $\mathrm{T}_{\mathrm{w}}$ is $0^{\circ}$ \\
\hline $\mathrm{Z}_{\mathrm{H}}$ Top & $\mathrm{Z}_{\mathrm{H}}$ value at $\mathrm{H}\left(\mathrm{Z}_{\mathrm{H}}\right.$ Top $)$ \\
\hline $\mathrm{Z}_{\mathrm{H}}$ Peak & $\mathrm{Z}_{\mathrm{H}}$ value at $\mathrm{H}\left(\mathrm{Z}_{\mathrm{H}}\right.$ Peak) (i.e., Maximum $\mathrm{Z}_{\mathrm{H}}$ in $\left.\mathrm{BB}\right)$ \\
\hline $\mathrm{Z}_{\mathrm{H}}$ Bottom & $\mathrm{Z}_{\mathrm{H}}$ value at $\mathrm{H}\left(\mathrm{Z}_{\mathrm{H}}\right.$ Bottom $)$ \\
\hline $\mathrm{Z}_{\mathrm{DR}}$ Top & $\mathrm{Z}_{\mathrm{DR}}$ value at $\mathrm{H}\left(\mathrm{Z}_{\mathrm{DR}}\right.$ Top $)$ \\
\hline$Z_{D R}$ Peak & $Z_{D R}$ value at $H\left(Z_{D R}\right.$ Peak) (i.e., Maximum $Z_{D R}$ in $B B$ ) \\
\hline $\mathrm{Z}_{\mathrm{DR}}$ Bottom & $\mathrm{Z}_{\mathrm{DR}}$ value at $\mathrm{H}\left(\mathrm{Z}_{\mathrm{DR}}\right.$ Bottom $)$ \\
\hline$\rho_{\mathrm{HV}}$ Top & $\rho_{\mathrm{HV}}$ value at $\mathrm{H}\left(\rho_{\mathrm{HV}}\right.$ Top $)$ \\
\hline$\rho_{\text {HV }}$ Peak & $\rho_{\mathrm{HV}}$ value at $\mathrm{H}\left(\rho_{\mathrm{HV}}\right.$ Peak) (i.e., Minimum $\rho_{\mathrm{HV}}$ in $\left.\mathrm{BB}\right)$ \\
\hline$\rho_{\mathrm{HV}}$ Bottom & $\rho_{\mathrm{HV}}$ value at $\mathrm{H}\left(\rho_{\mathrm{HV}}\right.$ Bottom $)$ \\
\hline
\end{tabular}

\section{Results and Discussion}

\subsection{Characterization of the $B B$}

\subsubsection{Height of the $\mathrm{BB}$}

The monthly average $\mathrm{H}\left(\mathrm{Z}_{\mathrm{H}}\right.$ Peak) is shown in Figure 4 and Table 3. The cold (warm) color indicates that the radar is located at higher (lower) latitude. All $\mathrm{H}\left(Z_{\mathrm{H}}\right.$ Peak) values in the warm season were higher than those in the cold season. The $\mathrm{H}\left(\mathrm{Z}_{\mathrm{H}}\right.$ Peak), which ranged from 4.14 to $4.71 \mathrm{~km}$, on average, during the summer, showed an annual variation with a peak in July or August. The mean $\mathrm{H}\left(\mathrm{Z}_{\mathrm{H}}\right.$ Peak) in March, April, and November was less than $3.0 \mathrm{~km}$, and that in September was greater than $4.0 \mathrm{~km}$. The differences in $\mathrm{H}\left(\mathrm{Z}_{\mathrm{H}}\right.$ Peak) among radars during the cold seasons were greater than those during warm seasons. Overall, the $\mathrm{H}\left(\mathrm{Z}_{\mathrm{H}}\right.$ Peak) from radars at higher latitudes was lower than that from radar at lower latitudes. The $\mathrm{H}\left(\mathrm{Z}_{\mathrm{H}}\right.$ Peak) at the GSN and SSP radars, which are located at relatively low latitudes, reached $4 \mathrm{~km}$ in May, whereas those at the KWK, MYN, KSN, PSN, and JNI radars exceeded $4 \mathrm{~km}$ in June. The $\mathrm{H}\left(\mathrm{Z}_{\mathrm{H}}\right.$ Peak) at the BRI and GDK radars, which are located at relatively high altitudes, exceeded $4 \mathrm{~km}$ in July. 


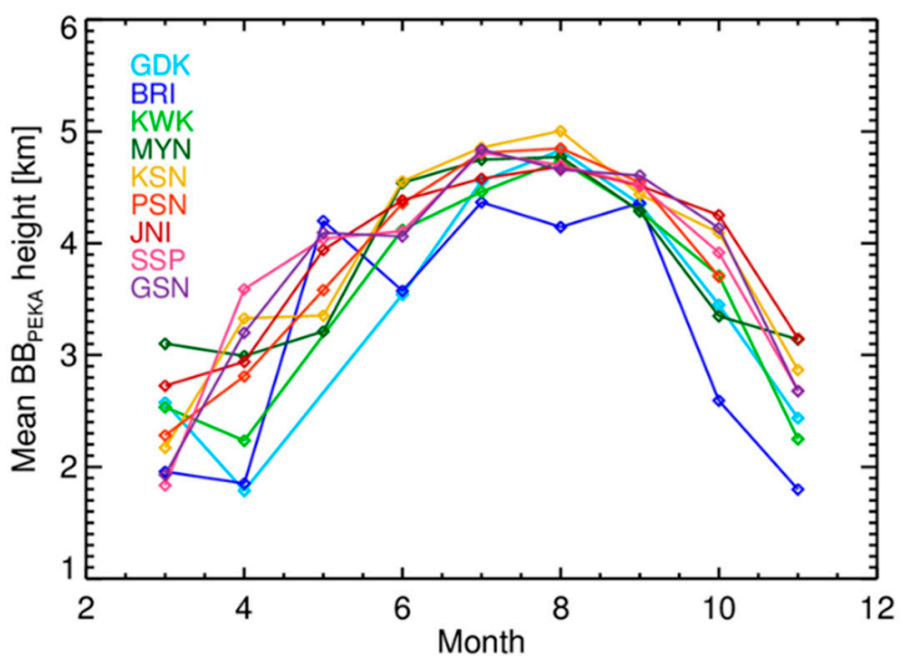

Figure 4. Monthly variation in mean height for $B B_{P E A K}$ identified using the $\mathrm{Z}_{\mathrm{H}}$ from March to November from the individual radar across the KMA weather radar network. The blue to red color indicates radar located from higher to lower latitudes.

Table 3. Monthly mean height of $\mathrm{BB}_{\text {PEAK }}$ at each radar sorted in ascending order according to latitude.

\begin{tabular}{cccccccccc}
\hline Radar & MAR & APR & MAY & JUN & JUL & AUG & SEP & OCT & NOV \\
\hline GDK & 2.58 & 1.79 & - & 3.54 & 4.56 & 4.83 & 4.35 & 3.45 & 2.44 \\
BRI & 1.96 & 1.85 & 4.20 & 3.57 & 4.37 & 4.15 & 4.36 & 2.59 & 1.80 \\
KWK & 2.53 & 2.24 & - & 4.12 & 4.46 & 4.74 & 4.29 & 3.71 & 2.25 \\
MYN & 3.10 & 2.99 & 3.21 & 4.54 & 4.75 & 4.77 & 4.29 & 3.35 & 3.14 \\
KSN & 2.17 & 3.33 & 3.35 & 4.55 & 4.86 & 5.00 & 4.44 & 4.09 & 2.87 \\
PSN & 2.28 & 2.81 & 3.58 & 4.36 & 4.81 & 4.85 & 4.55 & 3.70 & - \\
JNI & 2.73 & 2.94 & 3.94 & 4.39 & 4.58 & 4.68 & 4.51 & 4.25 & 3.15 \\
SSP & 1.83 & 3.59 & 4.04 & 4.11 & 4.81 & 4.70 & 4.52 & 3.92 & 2.68 \\
GSN & 1.93 & 3.20 & 4.09 & 4.06 & 4.84 & 4.66 & 4.61 & 4.14 & 2.68 \\
Mean & 2.35 & 2.75 & 3.77 & 4.14 & 4.67 & 4.71 & 4.43 & 3.69 & 2.62 \\
\hline
\end{tabular}

Figure 5 shows the two-dimensional frequency distribution between $\mathrm{H}\left(\mathrm{Z}_{\mathrm{DR}}\right.$ Peak $)$ and $\mathrm{H}\left(\mathrm{Z}_{\mathrm{H}}\right.$ Peak $)$ and between $\mathrm{H}\left(\rho_{\mathrm{HV}}\right.$ Peak) and $\mathrm{H}\left(\mathrm{Z}_{\mathrm{H}}\right.$ Peak). $\mathrm{H}\left(\mathrm{Z}_{\mathrm{H}}\right.$ Peak) was $70 \mathrm{~m}$ and $100 \mathrm{~m}$ higher than $\mathrm{H}\left(\mathrm{Z}_{\mathrm{DR}}\right.$ Peak $)$ and $\mathrm{H}\left(\rho_{\mathrm{HV}}\right.$ Peak), respectively. The $\mathrm{Z}_{\mathrm{H}}$ depends on the size, refractive index, and number concentration of hydrometeors in the melting layer. When the snowflakes enter the $0{ }^{\circ} \mathrm{C}$ isotherm layer, they start to melt at the tips of the crystal branches (mainly at the bottom side). Small snowflakes melt faster than large snowflakes, which boosts the aggregation and coalescence due to the difference in fall velocity. The $\mathrm{Z}_{\mathrm{H}}$ increase below the $0{ }^{\circ} \mathrm{C}$ isotherm layer is due to the increase in the particle size (aggregation) or number density (no aggregation). The maximum of the $\mathrm{Z}_{\mathrm{H}}$ results from melting particles covered by meltwater with a large size and a high dielectric constant. The fall velocity increases as large particles turn into raindrops below $Z_{H}$ Peak. This process reduces the $Z_{H}$ due to a decrease in the number concentration. In the $\mathrm{BB}$, the $\mathrm{Z}_{\mathrm{DR}}$ increases due to the oblate shape of the melting particles. The oblateness of the particles is maximized below $\mathrm{Z}_{\mathrm{H}}$ Peak (where their size is at maximum). The decrease in the $Z_{\mathrm{DR}}$ below the $\mathrm{BB}$ is due to the break-up of large melted snowflakes, since the $Z_{\mathrm{DR}}$ is not related to the number concentration. The $\rho_{\mathrm{HV}}$ begins to decrease when the snowflakes and raindrops mix to a sufficient degree; therefore, it occurs at a relatively lower altitude than where the $Z_{H}$ starts to increase via melting $[16,21]$. In other words, the $Z_{H}$ depends on the change in size and number concentration of melting snowflakes, whereas the $Z_{\mathrm{DR}}$ and $\rho_{\mathrm{HV}}$ are subject to the non-spherical shape of melting snowflakes. The mean height difference between $B_{\text {PEAK }}$ from the $Z_{H}$ and $\rho_{\mathrm{HV}}$ was $100 \mathrm{~m}$ in this study, which is consistent with the heights of 90,96 , and $121 \mathrm{~m}$ obtained in previous studies $[21,33,34]$. BB detection based on the $\rho_{\mathrm{HV}}$ can cause the underestimation of the height 
of the BB, as mentioned by Wolfensberger et al. [21]. According to Trömel et al. [26], the height of the maximum $\mathrm{Z}_{\mathrm{H}}$ was very close to that of the maximum backscatter differential phase $(\delta)$ and was higher than that of the minimum $\rho_{\mathrm{HV}}$. Trömel et al. [26] suggested that differences between heights should be analyzed in various climatic conditions to determine whether the aforementioned phenomenon is caused by differences in microphysical processes.
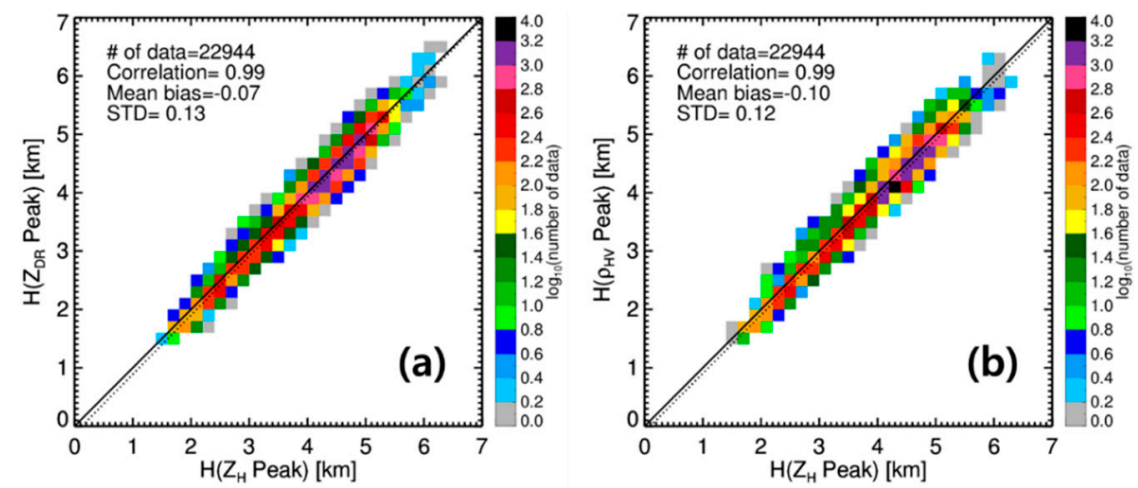

Figure 5. Two-dimensional frequency distribution (a) between $\mathrm{H}\left(\mathrm{Z}_{\mathrm{DR}}\right.$ Peak) and $\mathrm{H}\left(\mathrm{Z}_{\mathrm{H}}\right.$ Peak) and (b) between $\mathrm{H}\left(\rho_{\mathrm{HV}}\right.$ Peak) and $\mathrm{H}\left(\mathrm{Z}_{\mathrm{H}}\right.$ Peak).

Figure 6 shows the difference between $\mathrm{H}\left(\mathrm{Z}_{\mathrm{H}}\right.$ Peak) and $\mathrm{H}\left(\mathrm{Z}_{\mathrm{DR}}\right.$ Peak) (black line), and that between $\mathrm{H}\left(\mathrm{Z}_{\mathrm{H}}\right.$ Peak) and $\mathrm{H}\left(\rho_{\mathrm{HV}}\right.$ Peak) (red line) as a function of $\mathrm{Z}_{\mathrm{H}}$ Bottom. The black (red) dotted line indicates no difference (the mean difference in heights shown in Figure 5$). H\left(Z_{D R}\right.$ Peak) was almost identical to $\mathrm{H}\left(\mathrm{Z}_{\mathrm{H}}\right.$ Peak) in the range of 10 to $15 \mathrm{dBZ}$, whereas it was lower than $290 \mathrm{~m}$ than $\mathrm{H}\left(\mathrm{Z}_{\mathrm{H}}\right.$ Peak $)$ in the range of 35 to $40 \mathrm{dBZ}$. However, $\mathrm{H}\left(\rho_{\mathrm{HV}}\right.$ Peak) differed from $\mathrm{H}\left(\mathrm{Z}_{\mathrm{H}}\right.$ Peak) by more than $60 \mathrm{~m}(200 \mathrm{~m})$ in the range of 10 to $15 \mathrm{dBZ}$ ( 35 to $40 \mathrm{dBZ}$ ). In summary, according to Figures 5 and $6, \mathrm{H}\left(\mathrm{Z}_{\mathrm{H}}\right.$ Peak), $\mathrm{H}\left(\mathrm{Z}_{\mathrm{DR}}\right.$ Peak $)$, and $\mathrm{H}\left(\rho_{\mathrm{HV}}\right.$ Peak $)$ did not match. The difference in heights of $\mathrm{BB}_{\text {PEAK }}$ increased with increasing $Z_{\mathrm{H}}$ Bottom. The larger size and higher number concentration of melting snowflakes result in more significant differences in the height of $\mathrm{BB}_{\mathrm{PEAK}}$ based on polarimetric observations.
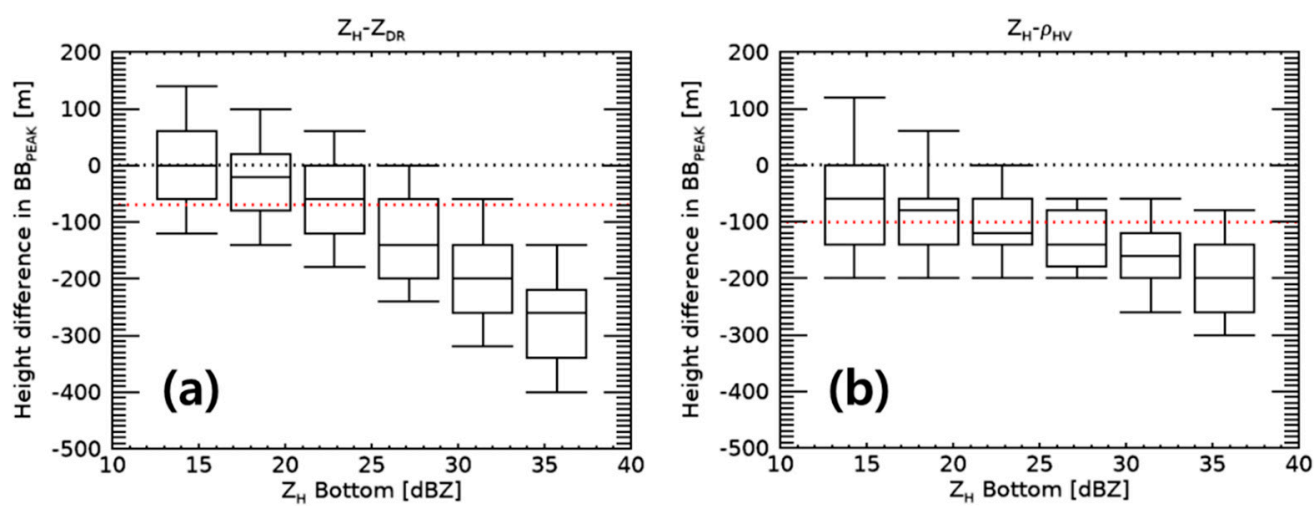

Figure 6. Box plots of the mean differences between $\mathrm{H}\left(\mathrm{Z}_{\mathrm{H}}\right.$ Peak) and $\mathrm{H}\left(\mathrm{Z}_{\mathrm{DR}}\right.$ Peak) (a), and between $\mathrm{H}\left(\mathrm{Z}_{\mathrm{H}}\right.$ Peak) and $\mathrm{H}\left(\rho_{\mathrm{HV}}\right.$ Peak) $(\mathbf{b})$ as a function of $\mathrm{Z}_{\mathrm{H}}$ Bottom. The black (red) dotted line indicates no difference (the mean height difference).

\subsubsection{Geometric Structure of the BB}

The heights of $\mathrm{BB}_{\mathrm{TOP}}, \mathrm{BB}_{\mathrm{PEAK}}$, and $\mathrm{BB}_{\mathrm{BOTTOM}}$ were analyzed to characterize the vertical structure of the $\mathrm{BB}$. Figure 7 shows the frequency distributions among the heights of $\mathrm{BB}_{\mathrm{TOP}}, \mathrm{BB}_{\mathrm{BOTTOM}}$, and $\mathrm{BB}_{\text {PEAK }}$ for $\mathrm{Z}_{\mathrm{H}}, \mathrm{Z}_{\mathrm{DR}}$, and $\rho_{\mathrm{HV}}$, respectively. $\mathrm{BB}_{\mathrm{TOP}}$ was $430-460 \mathrm{~m}$ higher than $\mathrm{BB}_{\mathrm{PEAK}}$, and $\mathrm{BB}_{\mathrm{BOTTOM}}$ was $340 \mathrm{~m}$ lower than $\mathrm{BB}_{\mathrm{PEAK}}$ on average, indicating that the structure of the $\mathrm{BB}$ was asymmetric. Physically, the melting particles spend more time covering the thin shell of meltwater around them, while they 
rapidly collapse to form a raindrop at the final stage of melting. The difference between the heights of $\mathrm{BB}_{\mathrm{TOP}}$ and $\mathrm{BB}_{\mathrm{BOTTOM}}$ is considered to be the $\mathrm{BB}$ thickness, and the relative position ( $\mathrm{r}$ ) is considered to be the difference between the heights of $\mathrm{BB}_{\text {PEAK }}$ and $\mathrm{BB}_{\mathrm{BOTTOM}}$ to the $\mathrm{BB}$ thickness as expressed below:

$$
\mathrm{r}=\left(\mathrm{H}\left(\mathrm{BB}_{\text {PEAK }}\right)-\mathrm{H}\left(\mathrm{BB}_{\mathrm{BOTTOM}}\right)\right) / \mathrm{BB} \text { thickness }
$$
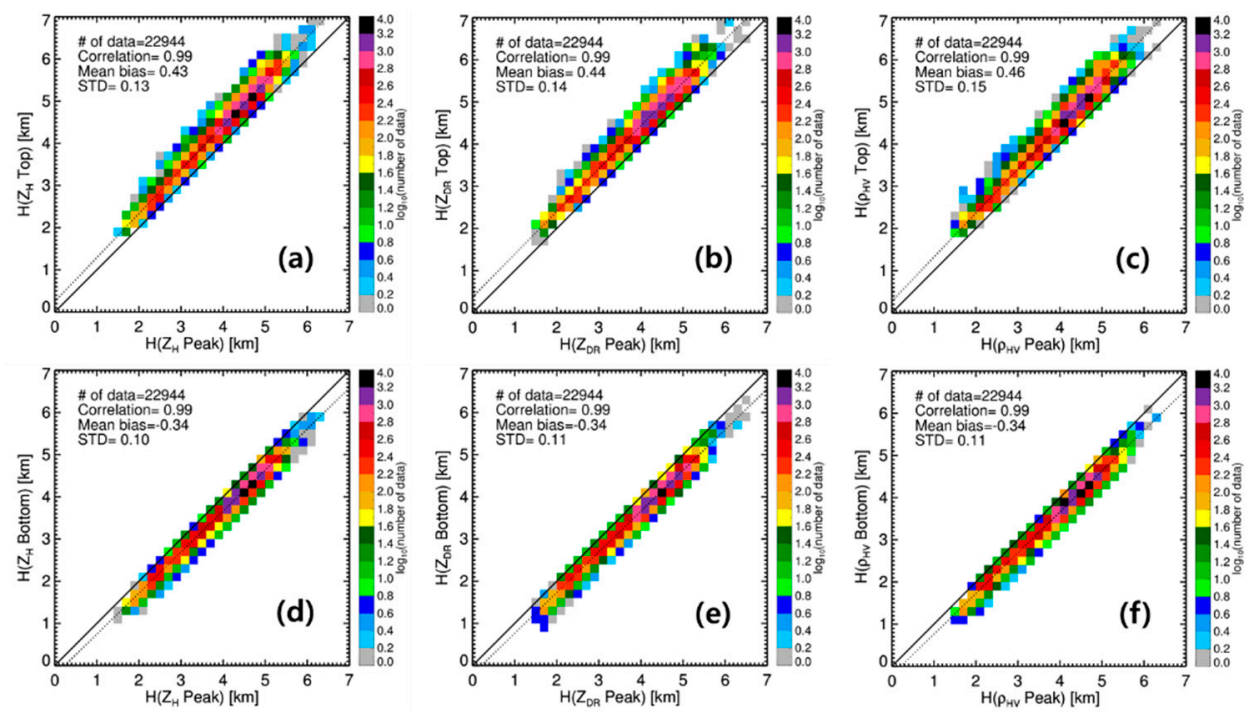

Figure 7. Two-dimensional frequency distributions. (a) Between $\mathrm{H}\left(\mathrm{Z}_{\mathrm{H}}\right.$ Top) and $\mathrm{H}\left(\mathrm{Z}_{\mathrm{H}}\right.$ Peak); (b) Between $\mathrm{H}\left(\mathrm{Z}_{\mathrm{DR}}\right.$ Top) and $\mathrm{H}\left(\mathrm{Z}_{\mathrm{DR}}\right.$ Peak); (c) Between $\mathrm{H}\left(\rho_{\mathrm{HV}}\right.$ Top) and $\mathrm{H}\left(\rho_{\mathrm{HV}}\right.$ Peak); (d) Between $\mathrm{H}\left(\mathrm{Z}_{\mathrm{H}}\right.$ Bottom) and $\mathrm{H}\left(\mathrm{Z}_{\mathrm{H}}\right.$ Peak); (e) Between $\mathrm{H}\left(\mathrm{Z}_{\mathrm{DR}}\right.$ Bottom) and $\mathrm{H}\left(\mathrm{Z}_{\mathrm{DR}}\right.$ Peak); and (f) between $\mathrm{H}\left(\rho_{\mathrm{HV}}\right.$ Bottom $)$ and $\mathrm{H}\left(\rho_{\mathrm{HV}}\right.$ Peak $)$.

Figure 8 shows box plots of the BB's thickness (left) and $r$ (right) according to $Z_{\mathrm{H}}$ Bottom at intervals of $5 \mathrm{~dB}$. For the $Z_{\mathrm{H}}$ and $Z_{\mathrm{DR}}$, the thicknesses of the $\mathrm{BB}$ increased with increasing $Z_{\mathrm{H}}$ Bottom. The weak $Z_{H}$ in the $B B$ represents non-aggregated snowflakes that are small in size. On the one hand, small snowflakes melt quickly and result in a thin BB. On the other hand, heavily aggregated snowflakes cause a thick and strong $B B$ due to the fact that they need more time to completely melt than small particles. Interestingly, the $B B$ thickness slowly increased until $20 \mathrm{dBZ}$, and rapidly increased above $20 \mathrm{dBZ}$, as shown in [34]. The BB thickness estimated using the $Z_{\mathrm{H}}$ and $Z_{\mathrm{DR}}$ exceeded $980 \mathrm{~m}$ and $870 \mathrm{~m}$ in the $35-40 \mathrm{dBZ}$ range of $Z_{\mathrm{H}}$ Bottom. The BB thickness estimated using $\rho_{\mathrm{HV}}$ was $800 \mathrm{~m}$ in the $10-15 \mathrm{dBZ}$ range of $Z_{\mathrm{H}}$ Bottom and $875 \mathrm{~m}$ in the $35-40 \mathrm{dBZ}$ range of $Z_{\mathrm{H}}$ Bottom. The $\rho_{\mathrm{HV}}$ related to the diversity of hydrometeors had a relatively constant thickness regardless of $Z_{\mathrm{H}}$ at $B B_{\text {ВОттом }}$ and a smaller variation as compared with the $Z_{H}$ and $Z_{D R}$. The $r$ was 0.45 for the $Z_{H}$ and $\rho_{H V}$ regardless of $\mathrm{Z}_{\mathrm{H}}$ Bottom, and $\mathrm{BB}_{\text {PEAK }}$ was closer to $\mathrm{BB}_{\mathrm{BOTTOM}}$ than $\mathrm{BB}_{\mathrm{TOP}}$. The $\mathrm{r}$ of the $\mathrm{Z}_{\mathrm{DR}}$ decreased from 0.5 to 0.4 as $Z_{\mathrm{H}}$ Bottom increased from the range of $10-15 \mathrm{dBZ}$ to $35-40 \mathrm{dBZ}$. The non-symmetric structure of the $Z_{\mathrm{DR}}$ resulted from a rapid decrease in the $Z_{\mathrm{DR}}$, due to the break-up of large melted particles at the final state of melting process [34]. 

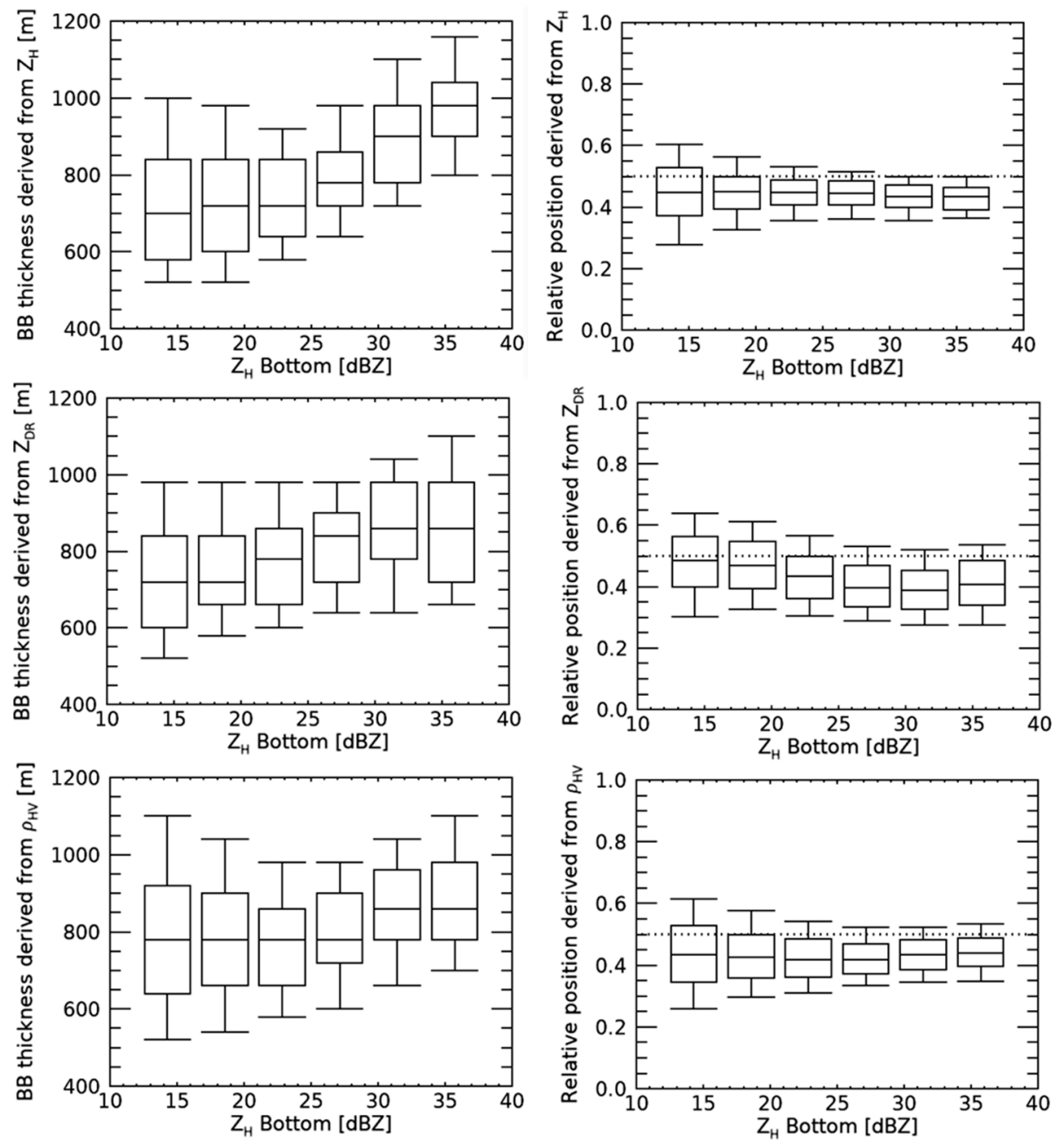

Figure 8. Box plots of the thickness of the $\mathrm{BB}$ (left) and relative position of $\mathrm{BB}_{\mathrm{PEAK}}$ (right) as a function of $\mathrm{Z}_{\mathrm{H}} \mathrm{BB}_{\mathrm{BOTTOM}}$. The dashed line indicates the symmetric structure of the $\mathrm{BB}$.

\subsubsection{Thermodynamic Characteristic of the BB}

The seasonal variability of the height of the $\mathrm{BB}$ depends on the ground temperature. To further analyze the thermodynamic characteristics of the $\mathrm{BB}$, we compared $\mathrm{H}\left(\mathrm{T}=0{ }^{\circ} \mathrm{C}\right), \mathrm{H}\left(\mathrm{T}_{\mathrm{w}}=0{ }^{\circ} \mathrm{C}\right)$, $\mathrm{H}\left(\mathrm{Z}_{\mathrm{H}}\right.$ Top), and $\mathrm{H}\left(\mathrm{Z}_{\mathrm{H}}\right.$ Peak) (Figures 9 and 10$) . \mathrm{H}\left(\mathrm{T}=0{ }^{\circ} \mathrm{C}\right)$ appears between $\mathrm{H}\left(\mathrm{Z}_{\mathrm{H}}\right.$ Top) and $\mathrm{H}\left(\mathrm{Z}_{\mathrm{H}}\right.$ Bottom $)$, and $\mathrm{H}\left(\mathrm{T}_{\mathrm{w}}=0^{\circ} \mathrm{C}\right)$ is close to $\mathrm{H}\left(\mathrm{Z}_{\mathrm{H}}\right.$ Peak). $\mathrm{H}\left(\mathrm{Z}_{\mathrm{H}} \mathrm{Top}\right)\left(\mathrm{H}\left(\mathrm{Z}_{\mathrm{H}}\right.\right.$ Peak $\left.)\right)$ presented at $300 \mathrm{~m}$ $(130 \mathrm{~m})$ above (below) $\mathrm{H}\left(\mathrm{T}=0^{\circ} \mathrm{C}\right)$ on average with a standard deviation of $320 \mathrm{~m}(300 \mathrm{~m})$. As compared with the NWP in [10], $\mathrm{H}\left(\mathrm{Z}_{\mathrm{H}}\right.$ Peak) appeared at $100 \mathrm{~m}$ below $\mathrm{H}\left(\mathrm{T}=0{ }^{\circ} \mathrm{C}\right)$, on average, with a standard deviation of $386 \mathrm{~m}$. As observed by Zhang et al. [10], the top height of the BB exceeded the $0{ }^{\circ} \mathrm{C}$ altitude owing to the beam spreading effect. $\mathrm{H}\left(\mathrm{T}_{\mathrm{w}}=0{ }^{\circ} \mathrm{C}\right)$ was located $470 \mathrm{~m}$ below $\mathrm{H}\left(\mathrm{Z}_{\mathrm{H}}\right.$ Top $)$ and $30 \mathrm{~m}$ below $\mathrm{H}\left(\mathrm{Z}_{\mathrm{H}}\right.$ Peak $)$, and $\mathrm{H}\left(\mathrm{T}_{\mathrm{w}}=0{ }^{\circ} \mathrm{C}\right)$ was closer to $\mathrm{H}\left(\mathrm{Z}_{\mathrm{H}}\right.$ Peak) than $\mathrm{H}\left(\mathrm{T}=0{ }^{\circ} \mathrm{C}\right)$. As mentioned in Zhang et. al. [10], the BB height detected from radars can be used to improve $\mathrm{T}$ for the numerical weather prediction (NWP).

The distributions of $\mathrm{T}, \mathrm{T}_{\mathrm{d}}$, and $\mathrm{T}_{\mathrm{w}}$ at $\mathrm{BB}_{\mathrm{TOP}}, \mathrm{BB}_{\mathrm{PEAK}}$, and $\mathrm{BB}_{\mathrm{BOTTOM}}$ are shown in Figure 11 , and Table 4 summarizes their mean and standard deviations. $\mathrm{BB}_{\mathrm{TOP}}$ and $\mathrm{BB}_{\text {PEAK }}$ corresponded to temperatures ranging from -1.96 to $-1.03{ }^{\circ} \mathrm{C}$ and 0.73 to $1.16^{\circ} \mathrm{C}$, respectively. The average $\mathrm{T}$ at $\mathrm{BB}_{\mathrm{BOTTOM}}$ ranged from 2.41 to $2.84^{\circ} \mathrm{C}$. The average $\mathrm{T}_{\mathrm{d}}$ at $\mathrm{BB}_{\mathrm{TOP}}, \mathrm{BB}_{\mathrm{PEAK}}$, and $\mathrm{BB}_{\mathrm{BOTTOM}}$ ranged from -2.90 to $-2.60{ }^{\circ} \mathrm{C}$, from -0.89 to $-0.49{ }^{\circ} \mathrm{C}$, and from 0.64 to $1.03{ }^{\circ} \mathrm{C}$. $\mathrm{T}_{\mathrm{d}}$ refers to a longer tail on the left side of the distribution, with a standard deviation exceeding $3.00^{\circ} \mathrm{C}$. The average $\mathrm{T}_{\mathrm{w}}$ at $\mathrm{BB}_{\mathrm{TOP}}$ $\left(\mathrm{BB}_{\text {PEAK }}\right.$ and $\left.\mathrm{BB}_{\text {BOTTOM }}\right)$ was -2.03 to $-1.73{ }^{\circ} \mathrm{C}\left(-0.04\right.$ to $0.37^{\circ} \mathrm{C}$ and 1.53 to $\left.1.93{ }^{\circ} \mathrm{C}\right)$. 

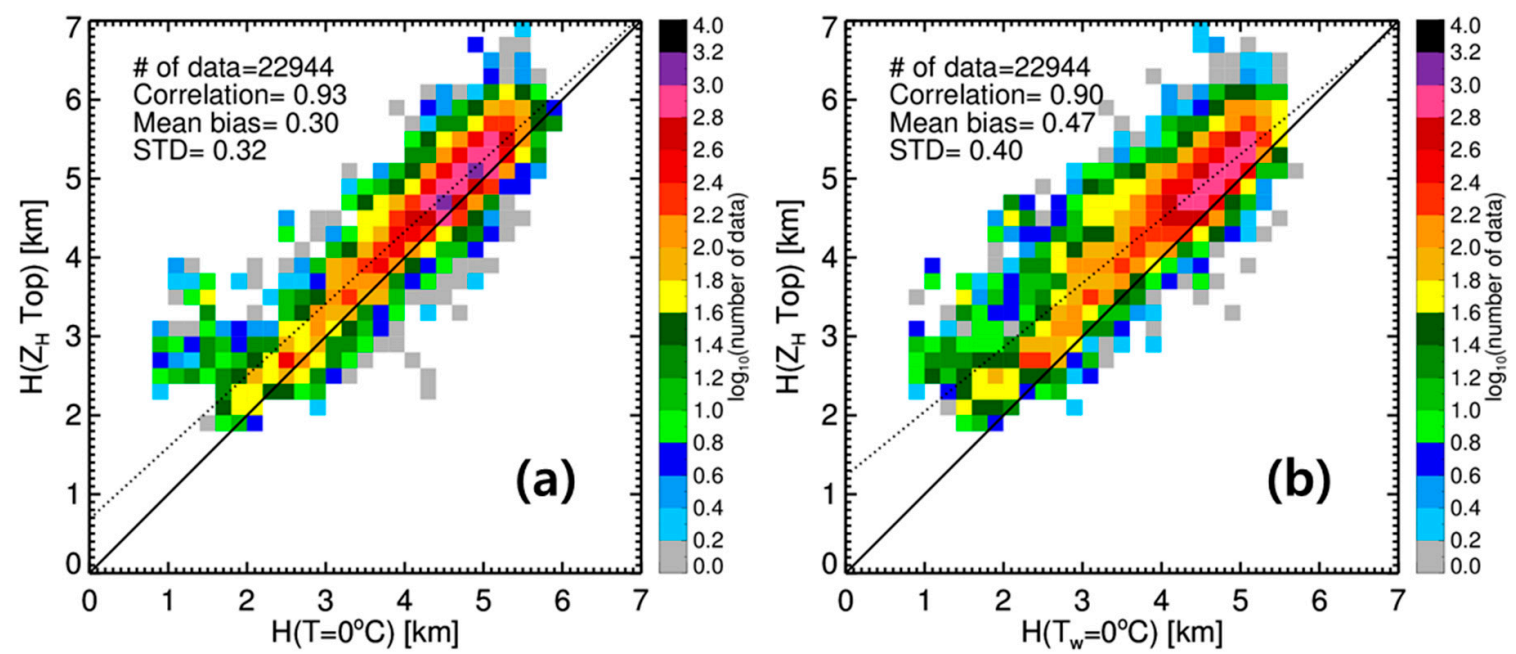

Figure 9. Two-dimensional frequency distributions between $(\mathbf{a}) \mathrm{H}\left(\mathrm{Z}_{\mathrm{H}}\right.$ Top $)$ and $\mathrm{H}\left(\mathrm{T}=0{ }^{\circ} \mathrm{C}\right)$ and between $(\mathbf{b}) \mathrm{H}\left(\mathrm{Z}_{\mathrm{H}} \mathrm{Top}\right)$ and $\mathrm{H}\left(\mathrm{T}_{\mathrm{w}}=0^{\circ} \mathrm{C}\right)$.
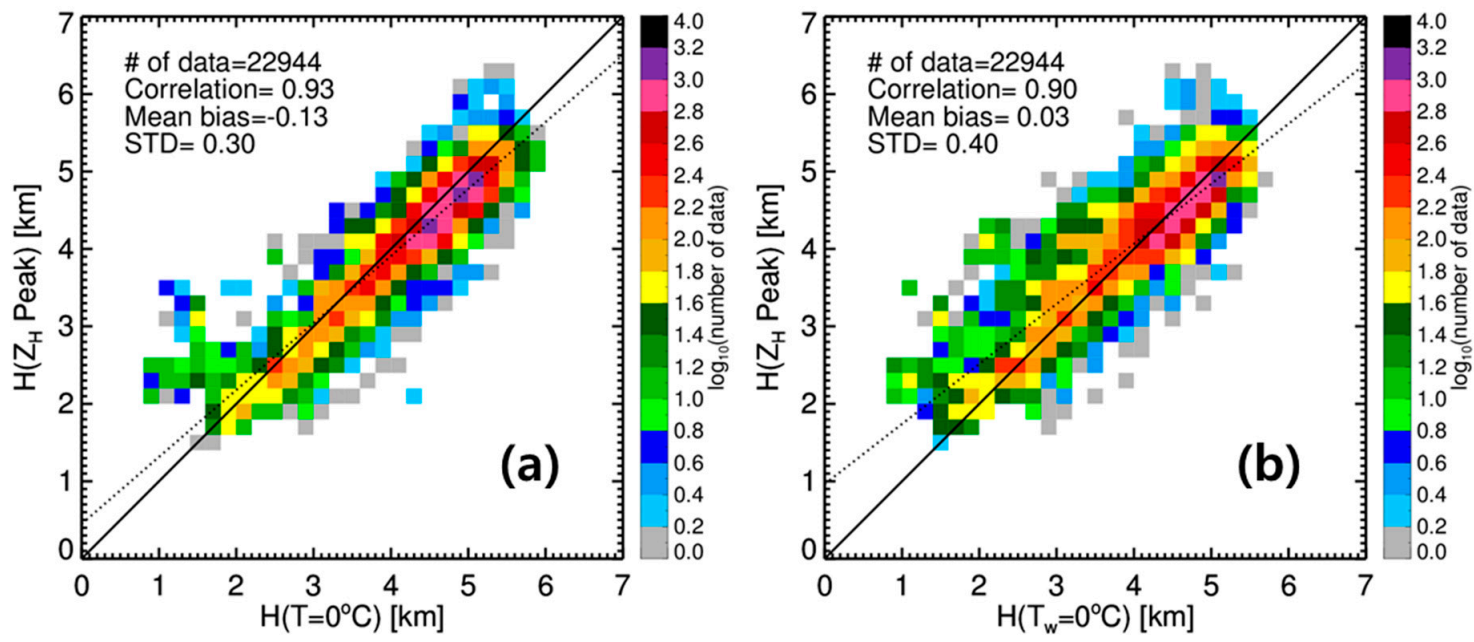

Figure 10. Two-dimensional frequency distributions between $(\mathbf{a}) \mathrm{H}\left(\mathrm{Z}_{\mathrm{H}}\right.$ Peak) and $\mathrm{H}\left(\mathrm{T}=0{ }^{\circ} \mathrm{C}\right)$ and between (b) $\mathrm{H}\left(\mathrm{Z}_{\mathrm{H}}\right.$ Peak) and $\mathrm{H}\left(\mathrm{T}_{\mathrm{w}}=0{ }^{\circ} \mathrm{C}\right)$.

Table 4. Mean and standard deviation (STD) of temperature $(T)$, dew point temperature $\left(T_{d}\right)$, and wet-bulb temperature $\left(\mathrm{T}_{\mathrm{W}}\right)$ at the top, peak, and bottom of the BB.

\begin{tabular}{|c|c|c|c|c|c|c|c|c|c|}
\hline \multirow{3}{*}{$\begin{array}{l}\text { MEAN } \\
\text { STD }\end{array}$} & \multicolumn{3}{|c|}{$\begin{array}{c}\text { T at } \\
\mathrm{H}\left(\mathrm{Z}_{\mathrm{H}} \text { Bottom/Peak/Top }\right)\end{array}$} & \multicolumn{3}{|c|}{$\begin{array}{c}\mathrm{T}_{\mathrm{d}} \text { at } \\
\mathrm{H}\left(\mathrm{Z}_{\mathrm{H}} \text { Bottom/Peak/Top }\right)\end{array}$} & \multicolumn{3}{|c|}{$\begin{array}{c}\mathrm{T}_{\mathrm{w}} \text { at } \\
\mathrm{H}\left(\mathrm{Z}_{\mathrm{H}} \text { Bottom/Peak/Top }\right)\end{array}$} \\
\hline & 2.41 & 0.73 & -1.33 & 0.64 & -0.89 & -2.90 & 1.53 & -0.04 & -2.03 \\
\hline & 1.55 & 1.32 & 1.39 & 3.34 & 3.24 & 3.36 & 1.71 & 1.52 & 1.58 \\
\hline & \multicolumn{3}{|c|}{$\begin{array}{c}\mathrm{T} \text { at } \\
\mathrm{H}\left(\mathrm{Z}_{\mathrm{DR}} \text { Bottom/Peak/Top }\right)\end{array}$} & \multicolumn{3}{|c|}{$\begin{array}{c}\mathrm{T}_{\mathrm{d}} \text { at } \\
\mathrm{H}\left(\mathrm{Z}_{\mathrm{DR}} \text { Bottom/Peak/Top }\right)\end{array}$} & \multicolumn{3}{|c|}{$\begin{array}{c}\mathrm{T}_{\mathrm{w}} \text { at } \\
\mathrm{H}\left(\mathrm{Z}_{\mathrm{DR}} \text { Bottom/Peak/Top }\right)\end{array}$} \\
\hline MEAN & 2.71 & 1.04 & -1.96 & 0.92 & -0.61 & -2.63 & 1.82 & 0.25 & -1.76 \\
\hline \multirow[t]{2}{*}{ STD } & 1.63 & 1.47 & 1.42 & 3.39 & 3.31 & 3.38 & 1.79 & 1.65 & 1.60 \\
\hline & \multicolumn{3}{|c|}{$\begin{array}{c}\text { T at } \\
\mathrm{H}\left(\rho_{\mathrm{HV}} \text { Bottom/Peak/Top }\right)\end{array}$} & \multicolumn{3}{|c|}{$\begin{array}{c}\mathrm{T}_{\mathrm{d}} \text { at } \\
\mathrm{H}\left(\rho_{\mathrm{HV}} \text { Bottom/Peak/Top }\right)\end{array}$} & \multicolumn{3}{|c|}{$\begin{array}{c}\mathrm{T}_{\mathrm{w}} \text { at } \\
\mathrm{H}\left(\rho_{\mathrm{HV}} \text { Bottom/Peak/Top }\right)\end{array}$} \\
\hline MEAN & 2.84 & 1.16 & -1.03 & 1.03 & -0.49 & -2.60 & 1.93 & 0.37 & -1.73 \\
\hline STD & 1.65 & 1.44 & 1.51 & 3.39 & 3.28 & 3.40 & 1.79 & 1.60 & 1.69 \\
\hline
\end{tabular}



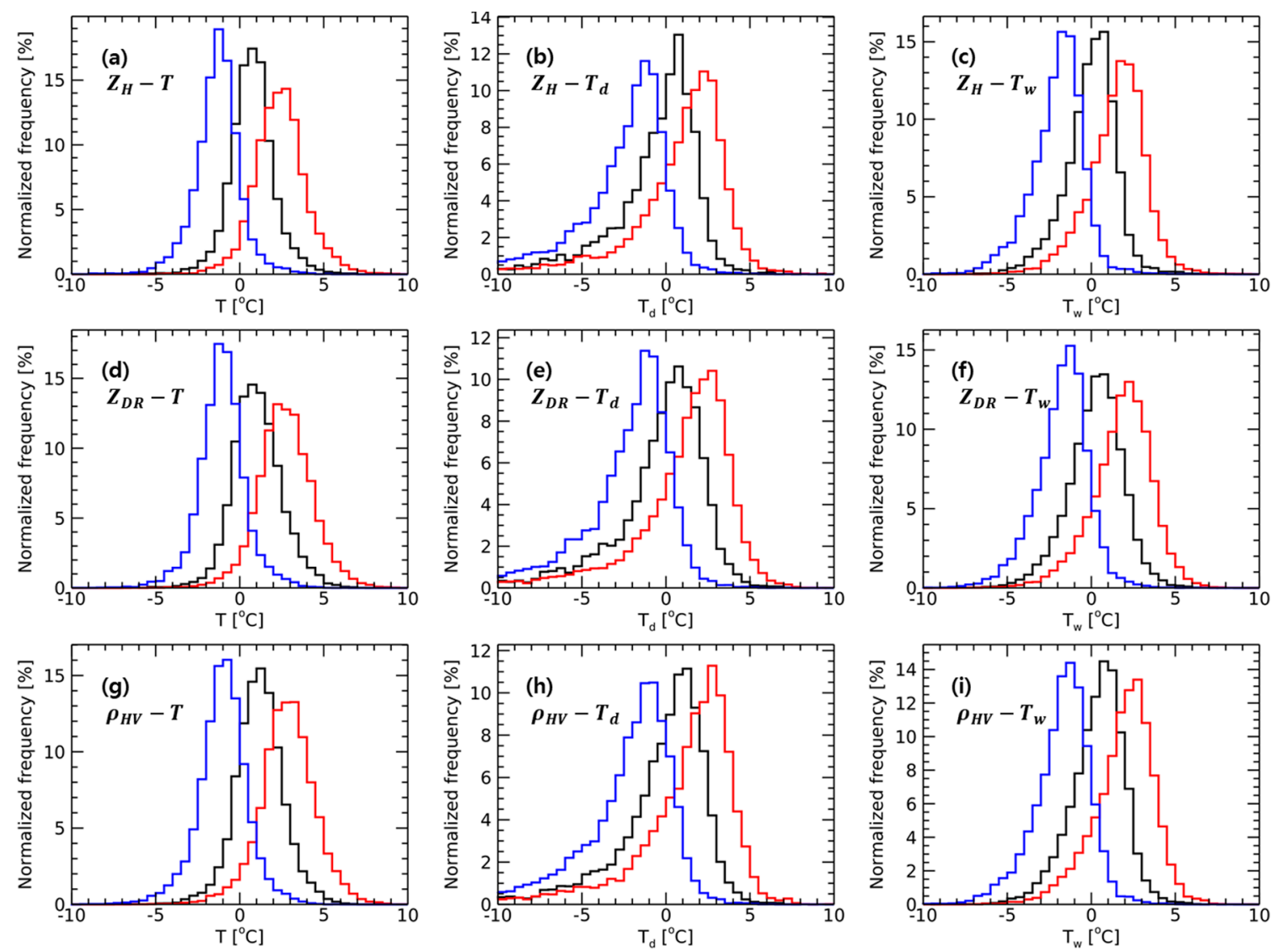

Figure 11. Normalized frequency distribution of $(\mathbf{a}, \mathbf{d}, \mathbf{g}) \mathrm{T},(\mathbf{b}, \mathbf{e}, \mathbf{h}) \mathrm{T}_{\mathrm{d}}$, and $(\mathbf{c}, \mathbf{f}, \mathbf{i}) \mathrm{T}_{\mathrm{w}}$ at top (blue), peak (black), and bottom (red) of bright band from QVPs of $(\mathbf{a}-\mathbf{c}) Z_{\mathrm{H}},(\mathbf{d}-\mathbf{f}) Z_{\mathrm{DR}}$, and $(\mathbf{g}-\mathbf{i}) \rho_{\mathrm{HV}}$.

\subsection{Polarimetric Observation of the $B B$}

The distributions of polarimetric observations at $\mathrm{BB}_{\mathrm{TOP}}$ (blue), $\mathrm{BB}_{\text {PEAK }}$ (black), and $\mathrm{BB}_{\text {BOTTOM }}$ (red) are shown in Figure 12. $Z_{\mathrm{H}}$ Peak mainly ranged between 10 and $45 \mathrm{dBZ}$, and the average $Z_{\mathrm{H}}$ Peak was $27.2 \mathrm{dBZ}$. The average $Z_{\mathrm{H}}$ Top $\left(Z_{\mathrm{H}}\right.$ Bottom) was $21.2 \mathrm{dBZ}(17.5 \mathrm{dBZ})$. The $Z_{\mathrm{H}}$, when the ice particles completely melted, was lower than that when they began to melt. $Z_{\mathrm{DR}}$ Peak was distributed between 0.0 and $3.0 \mathrm{~dB}$ with an average of $1.28 \mathrm{~dB}$. The average values of $Z_{\mathrm{DR}}$ Top and $Z_{\mathrm{DR}}$ Bottom were almost similar $(0.26$ and $0.24 \mathrm{~dB})$. The melting snowflakes were observed to be more oblate than snowflakes and raindrops. $\rho_{\mathrm{HV}}$ Peak was distributed between the range of 0.86 and 0.97 and was 0.92 on average. The average $\rho_{\mathrm{HV}}$ Top and $\rho_{\mathrm{HV}}$ Bottom, which are the threshold values commonly used for BB detection, were identical (0.97).
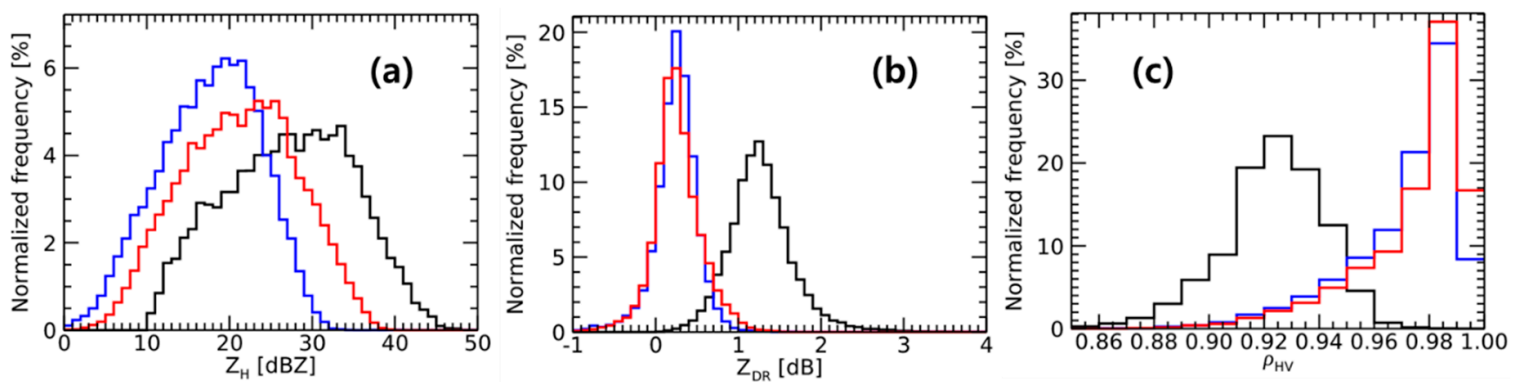

Figure 12. Normalized frequency distribution of (a) $\mathrm{Z}_{\mathrm{H}},(\mathbf{b}) \mathrm{Z}_{\mathrm{DR}}$, and (c) $\rho_{\mathrm{HV}}$ at top (blue), peak (black), and bottom (red) of the BB. 
The results were compared with those obtained under various climatic conditions. In [21,26], the authors used X-band radar and [27] used S-band radar to analyze the BB. [21] detected the BB using RHI data from Davos (Swiss Alps), Ardeche (South of France), Iowa (Midwestern USA), and Payerne (Swiss Plateau). Ref. [26] constructed the QVPs from a radar located in Born (Germany), while [27] constructed theirs from the WSR-88D radar in the USA. Their BB detection technique was very similar to that of [21,26], and [27] applied a technique based on the $\rho_{\mathrm{HV}}$. According to [27], QVP allows for more accurate quantification of polarimetric observations than RHI data. Therefore, the results of this study were comparable to those of previous studies. The distribution of $Z_{H}$ Peak, $Z_{D R}$ Peak, and $\rho_{\mathrm{HV}}$ Peak in Figure 12 were very similar to those in previous study. The average of $Z_{\mathrm{H}}$ Peak (27.2 dBZ) was slightly lower than that in the Payerne region (29.0 dBZ), higher than that in the Iowa region (25.46 dBZ), and higher than that obtained by [27] (25.42 dBZ). The average $\mathrm{Z}_{\mathrm{DR}}$ Peak (1.28 dB) was slightly different from that in the Ardeche region $(1.29 \mathrm{~dB})$ and that obtained by [27] $(1.13 \mathrm{~dB})$. The $\rho_{\mathrm{HV}}$ Peak (0.92) was higher than those obtained in Davos and Iowa (0.82), but very consistent with those obtained in the Born region (0.93) and [27] (0.94).

Figure 13 shows scatterplots between $\mathrm{Z}_{\mathrm{H}}$ Peak and $\mathrm{Z}_{\mathrm{H}}$ Top/Z $\mathrm{Z}_{\mathrm{H}}$ Bottom, $\mathrm{Z}_{\mathrm{DR}}$ Peak and $\mathrm{Z}_{\mathrm{DR}}$ Top/Z $\mathrm{Z}_{\mathrm{DR}}$ Bottom, and $\rho_{\mathrm{HV}}$ Peak and $\rho_{\mathrm{HV}}$ Top $/ \rho_{\mathrm{HV}}$ Bottom. The color of the diamond symbol indicates the $\mathrm{Z}_{\mathrm{H}}$ Peak. According to [27], a high $\mathrm{Z}_{\mathrm{H}}$ in the BB represented large snowflakes enlarged via aggregation, and a low $\mathrm{Z}_{\mathrm{H}}$ mainly represented pristine ice crystals. In addition, a high number of snowflake concentrations increased the number of raindrops after passing the BB. It is apparent from Figure 13a that the mean difference between $Z_{\mathrm{H}}$ Top and $\mathrm{Z}_{\mathrm{H}}$ Peak was 9.68, with a standard deviation of $2.88 \mathrm{~dB}$, and the mean difference between $Z_{H}$ Peak and $Z_{H}$ Bottom was $6.00 \mathrm{~dB}$ with a standard deviation of $2.49 \mathrm{~dB}$. Large snowflakes result in an intense BB, which leads to overestimation of rainfall at the surface. $Z_{D R}$ Top and $Z_{D R}$ Peak showed a correlation of 0.58 and a mean difference of $-1.04 \mathrm{~dB}$, while $Z_{D R}$ Peak and $Z_{D R}$ Bottom showed a correlation of 0.33. Large snowflakes with high $Z_{H}$ Bottom turn into large raindrops with high $Z_{\mathrm{DR}}$ Bottom. Large snowflakes grown by aggregation (represented by high $\mathrm{Z}_{\mathrm{H}}$ Peak) turn into large raindrops (high $\mathrm{Z}_{\mathrm{DR}}$ Bottom). In other words, the size of raindrops is related to the growth process of snowflakes above the BB. The difference between $\rho_{\mathrm{HV}}$ Peak and $\rho_{\mathrm{HV}}$ Top (between $\rho_{\mathrm{HV}}$ Peak and $\rho_{\mathrm{HV}}$ Bottom) increased even more as $Z_{\mathrm{H}}$ Peak increased. This results from the inhomogeneity of the hydrometeors' shape, orientation, and size within the BB since large snowflakes melt more slowly than small snowflakes. In addition, $\rho_{H V}$ Peak, $\rho_{H V}$ Top, and $\rho_{H V}$ Bottom with low $Z_{H}$ Bottom were similar (close to the 1:1 line). This mean that the $\rho_{H V}$ shows no distinctive signature for a weak BB.

Figure 14 represents the mean profiles of the (a) $Z_{H}$ and (b) $Z_{D R}$ at the $Z_{H}$ Bottom classes with $5 \mathrm{dBZ}$ intervals. $\mathrm{H}\left(\mathrm{Z}_{\mathrm{H}}\right.$ Peak) and $\mathrm{H}\left(\mathrm{Z}_{\mathrm{DR}}\right.$ Peak) are reference heights. The maximum $\mathrm{Z}_{\mathrm{H}}$ and $\mathrm{Z}_{\mathrm{DR}}$ were located at $0.0 \mathrm{~km}$. The difference in the $Z_{\mathrm{H}}$ above the $\mathrm{BB}$ and $\mathrm{Z}_{\mathrm{H}}$ Peak was greater than the difference in the $Z_{H}$ below the BB and $Z_{H}$ Peak. The intensity of the BB depended on $Z_{H}$ Bottom, and the $Z_{H}$ below the $\mathrm{BB}$ was almost constant at every class. The size and concentration of snowflakes determined the $Z_{H}$ structure of the $B B$ and the rainfall intensity below the $B B$. The $Z_{D R}$ decreased above the $B B$ as the snowflake particles smoothen when they start to melt. Large snowflakes (high $Z_{\mathrm{H}}$ Bottom class) with a high axis ratio have a low $Z_{D R}$ above the $B B$. The $Z_{D R}$ within the $B B$ with a high $Z_{H}$ Bottom class was greater than that with a low $Z_{H}$ Bottom class. The $Z_{D R}$ below the $B B$ was larger at the high $\mathrm{Z}_{\mathrm{H}}$ Bottom class. The shape and orientation of snowflakes determined the $\mathrm{Z}_{\mathrm{DR}}$ structure of the $\mathrm{BB}$. 

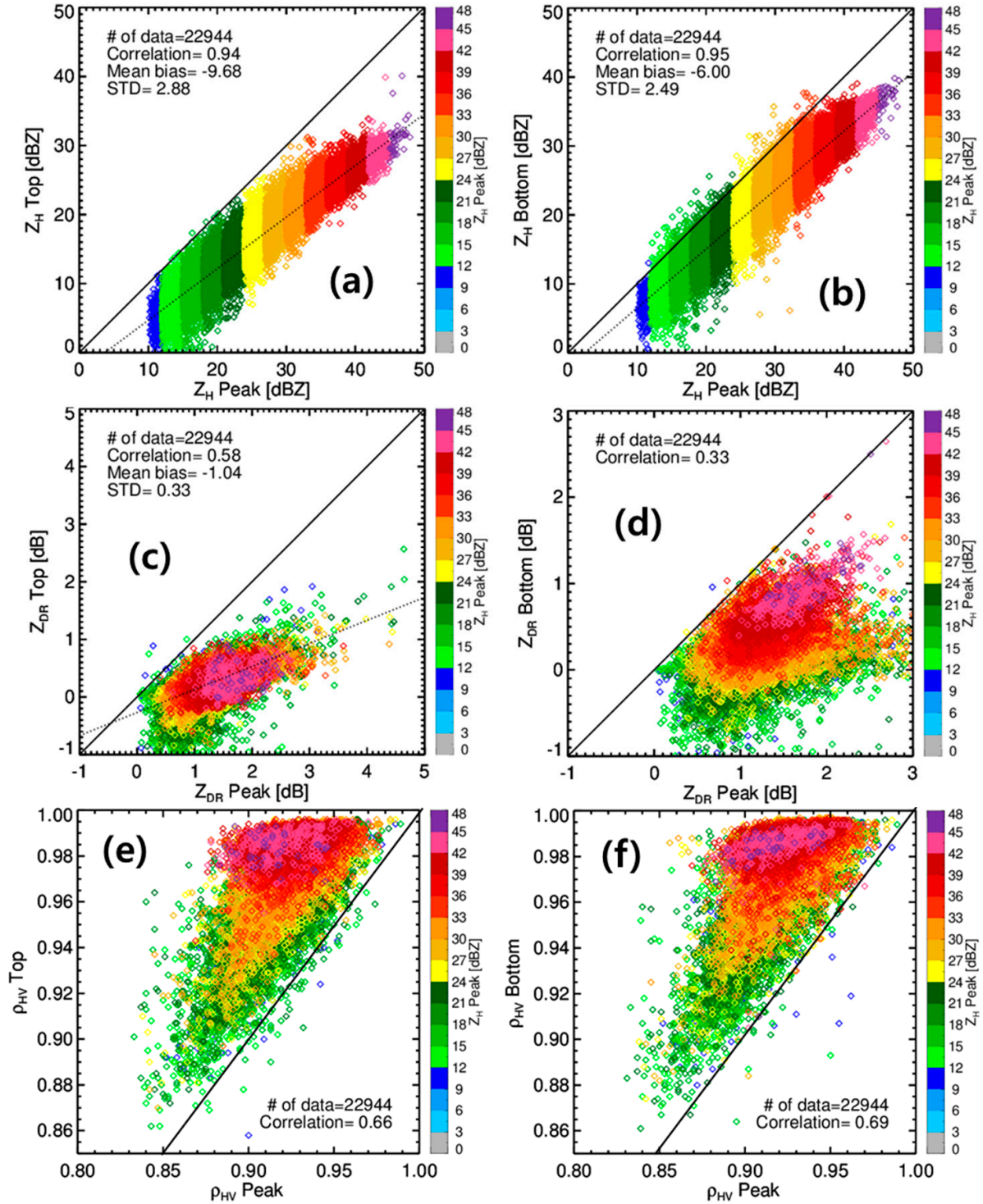

Figure 13. Scatter plots of (a) $Z_{H}$ Top and $Z_{H}$ Peak, (b) $Z_{D R}$ Top and $Z_{D R}$ Peak, (c) $\rho_{H V}$ Top and $\rho_{\mathrm{HV}}$ Peak, (d) $Z_{\mathrm{H}}$ Bottom and $Z_{\mathrm{H}}$ Peak, (e) $Z_{\mathrm{DR}}$ Bottom and $Z_{\mathrm{DR}}$ Peak, and (f) $\rho_{\mathrm{HV}}$ Bottom and $\rho_{\mathrm{HV}}$ Peak. Colors indicate the $\mathrm{Z}_{\mathrm{H}}$ Peak with $3 \mathrm{dBZ}$ intervals.
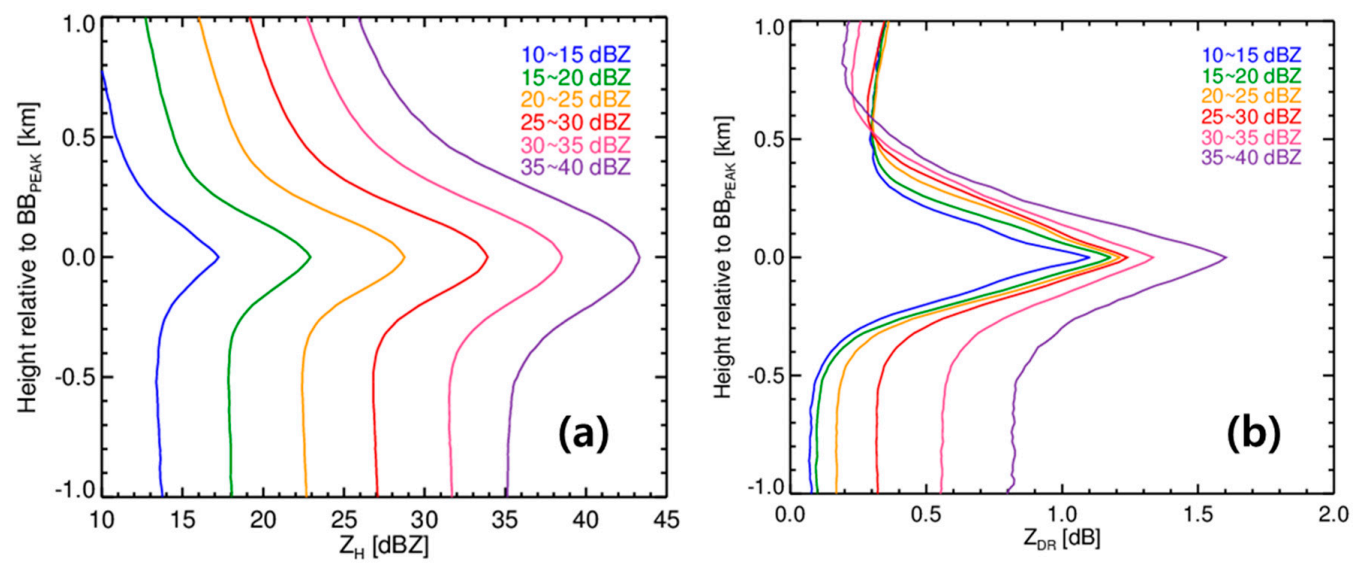

Figure 14. Mean profile of the (a) $Z_{H}$ and (b) $Z_{D R}$ with respect to the height relative to $B_{\text {PEAK }}$ at the $\mathrm{Z}_{\mathrm{H}}$ Bottom classes with $5 \mathrm{dBZ}$ intervals. 


\section{Conclusions}

In this study, we investigated the characteristics of BB in South Korea using QVPs from an operational S-band dual-polarization weather radar network. The BB was automatically identified based on the morphological features from the QVPs of polarimetric observations $\left(Z_{\mathrm{H}}, Z_{\mathrm{DR}}\right.$, and $\left.\rho_{\mathrm{HV}}\right)$ using the coordinate rotation technique proposed by [9], and their geometric, thermodynamic, and polarimetric characteristics were statistically examined. The polarimetric observations were corrected before constructing the QVPs for comparable analysis among weather radars in the network. First, the system calibration bias in power-related polarimetric observations $\left(Z_{H}\right.$ and $\left.Z_{D R}\right)$ was corrected based on the self-consistency principle between power- and phase-based measurements. Second, the $\rho_{\text {HV }}$ was biased at low SNR due to noise effects. The precipitation echoes yielded a value that was equal to or greater than 0.98 . Unfortunately, an abnormal $\rho_{\mathrm{HV}}$ was observed in meteorological echoes at a low SNR. The $\rho_{\mathrm{HV}}$ in low SNR areas was corrected using the SNR. Quality control was performed using the $\rho_{\mathrm{HV}}$ and SNR to minimize non-meteorological echoes, and then the $Z_{\mathrm{H}}, Z_{\mathrm{DR}}$, and $\rho_{\mathrm{HV}}$ were averaged in the azimuth direction to generate QVPs of polarimetric observations. The $\rho_{\mathrm{HV}}$ was converted to a new variable to apply the same procedure for the detection of the BB. In this study, the peak of the $\mathrm{BB}\left(\mathrm{BB}_{\mathrm{PEAK}}\right)$ was defined as the maximum value by calculating the first gradient. The top and bottom of the $\mathrm{BB}\left(\mathrm{BB}_{\mathrm{TO}}\right.$ and $\left.\mathrm{BB}_{\mathrm{BOTTOM}}\right)$ were identified via application of the coordinate rotation method developed by [9].

We analyzed the monthly mean height of $\mathrm{BB}_{\mathrm{PEAK}}$ for all radars in the KMA network. The heights of $\mathrm{BB}_{\text {PEAK }}$ showed a seasonal variation in all radars (e.g., the highest occurred in the summer). The maximum height of $\mathrm{BB}_{\mathrm{PEAK}}$ derived from the $\mathrm{Z}_{\mathrm{H}}$ was $5 \mathrm{~km}$, and the average heights varied within the range from 4.14 to $4.71 \mathrm{~km}$ in summer. However, they showed distinct differences depending on the location (e.g., latitude) and the altitude of the radar within the radar network, even in the same season. The heights of BB $\mathrm{PEAK}_{\mathrm{B}}$ differed among the polarimetric observations. The height where melting particles had the most oblate shapes ( $B_{\text {PEAK }}$ derived from $Z_{D R}$ ) were below that where their size was at maximum (BB ${ }_{\text {PEAK }}$ derived from $Z_{H}$ ). The inhomogeneity of the hydrometeors was also at maximum (BB PEAK derived from $\rho_{\mathrm{HV}}$ ) below $B B_{\text {PEAK }}$ derived from $Z_{H}$. The height difference of $B B_{P E A K}$ between the $Z_{H}$ and $Z_{D R}$, and that between $Z_{\mathrm{H}}$ and $\rho_{\mathrm{HV}}$ increased with increasing $Z_{\mathrm{H}}$ Bottom. The difference in heights of $Z_{\mathrm{H}}$ Peak and $\rho_{\mathrm{HV}}$ Peak was similar to that in previous studies under various climatic conditions.

The relative position ( $\mathrm{r}$ ) of $\mathrm{BB}_{\text {PEAK }}$ (defined as the height difference between $\mathrm{BB}_{\mathrm{PEAK}}$ and $\mathrm{BB}_{\mathrm{BOTTOM}}$ to the $\mathrm{BB}$ thickness) and the $\mathrm{BB}$ thickness were calculated to analyze the geometric characteristics of the BB. The difference in heights between BB $B_{\text {PEAK }}$ and BB $_{\text {TOP }}\left(B_{\text {BOTTOM}}\right)$ was 430-460 m (350 m). The $\mathrm{BB}$ thickness represented by the $\mathrm{Z}_{\mathrm{H}}$ and $\mathrm{Z}_{\mathrm{DR}}$ tended to increase with increasing $\mathrm{Z}_{\mathrm{H}}$ Bottom. The $\mathrm{r}$ was less than 0.5 for all variables, and BB $B_{\text {PEAK }}$ was close to BB BOTTOM. The $r$ for the QVP of $Z_{D R}$ was close to 0.5 if $Z_{\mathrm{H}}$ Bottom was low, and the $\mathrm{r}$ decreased to 0.4 if $\mathrm{Z}_{\mathrm{H}}$ Bottom was high. We confirmed from these results that the structure of the $\mathrm{BB}$ was asymmetrical and depended on $\mathrm{Z}_{\mathrm{H}}$ Bottom.

The thermodynamic characteristics were analyzed by comparing the BB heights and zero isothermal layers of dry-bulb, dew point, and wet-bulb temperatures. The zero-isotherm layer of the dry-bulb temperature was located between $\mathrm{BB}_{\mathrm{TOP}}$ and $\mathrm{BB}_{\mathrm{BOTTOM}}$ and was closer to the zero-isotherm layer of the welt-bulb temperature. $\mathrm{BB}_{\mathrm{TOP}}$ was located above the zero temperature $\left(-1.96\right.$ to $\left.-1.03{ }^{\circ} \mathrm{C}\right)$, and $\mathrm{BB}_{\text {PEAK }}$ was located below the zero temperature $\left(0.73\right.$ to $\left.1.16{ }^{\circ} \mathrm{C}\right)$.

The microphysical process associated with the $\mathrm{BB}$ was investigated by analyzing the polarimetric observations in the $\mathrm{BB}$. The polarimetric observations at $\mathrm{BB}_{\mathrm{PEAK}}$ were compared with those in previous studies. The distribution of polarimetric observations was very similar, although previous studies utilized different frequencies, radar scan strategies, and BB detection techniques. The $\mathrm{Z}_{\mathrm{H}}$ at $\mathrm{BB}_{\mathrm{PEAK}}$ averaged $27.2 \mathrm{~dB}$, with a difference of $9.68(6.00) \mathrm{dB}$ from that at $\mathrm{BB}_{\mathrm{TOP}}\left(\mathrm{BB}_{\mathrm{BOTTOM}}\right)$. The $\mathrm{Z}_{\mathrm{DR}}$ at $\mathrm{BB}_{\mathrm{PEAK}}$ was $1.28 \mathrm{~dB}$, which was higher than the $\mathrm{Z}_{\mathrm{DR}}$ at $\mathrm{BB}_{\mathrm{TOP}}(0.26 \mathrm{~dB})$ and $\mathrm{BB}_{\mathrm{BOTTOM}}(0.24 \mathrm{~dB})$. The $\rho_{\mathrm{HV}}$ at $\mathrm{BB}_{\mathrm{PEAK}}$ was 0.92, whereas that at $\mathrm{BB}_{\mathrm{TOP}}$ and $\mathrm{BB}_{\mathrm{BOTTOM}}$ was 0.97 , which is the threshold traditionally used for the detection of the $\mathrm{BB}$. The relation between polarimetric observations at $\mathrm{BB}_{\mathrm{PEAK}}, \mathrm{BB}_{\mathrm{TOP}}$, and $\mathrm{BB}_{\mathrm{BOTTOM}}$ represented the microphysical properties of the $\mathrm{BB}$. The $\mathrm{Z}_{\mathrm{H}}$ at $\mathrm{BB}_{\mathrm{PEAK}}, \mathrm{BB}_{\mathrm{TOP}}$, and $\mathrm{BB}_{\mathrm{BOTTOM}}$ was highly 
correlated. This means that large snowflakes turn into large raindrops. It was also confirmed that the $Z_{D R}$ at $\mathrm{BB}_{\mathrm{BOTTOM}}$ and $\mathrm{BB}_{\text {PEAK }}$ showed a positive relation with a high $\mathrm{Z}_{\mathrm{H}}$ at $\mathrm{BB}_{\text {PEAK}}$. The mean profiles of $\mathrm{Z}_{\mathrm{H}}$ and $Z_{\mathrm{DR}}$ also depended on the size and concentration of the snowflakes above the $\mathrm{BB}$.

In conclusion, the characteristics of BB from the QVPs of polarimetric observations were investigated in this study. The three-dimensional detection of $\mathrm{BB}$ and its intensity correction remain a challenge. Especially, this is more difficult in the cold season because the vertical structure of BB cannot be fully identified when they occur near the surface. The polarimetric observations above, within, and below the BB revealed in this study provide the characteristics of the BB related to microphysical processes. The results contribute by promoting an understanding of polarimetric signatures within $\mathrm{BB}$ and ultimately improve the performance of BB correction techniques. Furthermore, the NWP can represent the microphysical processes within $\mathrm{BB}$, and the zero isothermal layer identified from radar observations can be used for NWP data assimilation.

Author Contributions: This work was possible through significant contributions from all authors. Conceptualization, S.-H.J., J.-E.L. and S.K.; methodology, S.-H.J., J.-E.L. and S.K.; software, J.-E.L., S.-H.J. and S.K.; formal analysis, J.-E.L.; investigation, J.-E.L.; writing-original draft preparation, S.-H.J. and J.-E.L.; writing-review and editing, S.-H.J. and J.-E.L.; visualization, J.-E.L.; supervision, S.-H.J.; funding acquisition, S.-H.J. All authors have read and agreed to the published version of the manuscript.

Funding: This research is supported by "Development and application of cross governmental dual-pol radar harmonization (WRC-2013-A-1)" project of the Weather Radar Center, Korea Meteorological Administration.

Conflicts of Interest: The authors declare no conflict of interest.

\section{References}

1. Fabry, F.; Zawadzki, I. Long-term radar operations of the melting layer of precipitation and their interpretation. J. Atmos. Sci. 1995, 52, 838-851. [CrossRef]

2. Szyrmer, W.; Zawadzki, I. Modeling of the melting layer. Part I: Dynamics and microphysics. J. Atmos. Sci. 1999, 56, 3573-3592.

3. Bellon, A.; Lee, G.W.; Zawadzki, I. Error statistics of VPR corrections in stratiform precipitation. J. Appl. Meteor. 2005, 44, 998-1015. [CrossRef]

4. Germann, U.; Joss, J. Mesobeta profiles to extrapolate radar precipitation measurements above the Alps to the ground level. J. Appl. Meteor. 2002, 41, 542-557. [CrossRef]

5. Vignal, B.; Krajewski, W. Large-sample evaluation of two methods to correct range-dependent error for WSR-88D rainfall estimates. J. Hydrometeor. 2001, 2, 490-504. [CrossRef]

6. Tilford, K.A.; Cluckie, I.D.; Griffith, R.J.; Lane, A. Vertical reflectivity characteristics and bright band correction. In Radar Hydrology for Real Time Flood Forecasting, Proceedings of an Advanced Study Course; Griffith, R.J., Cluckie, I.D., Austin, G.L., Han, D., Eds.; EUR-OP: Luxembourg, 2001; pp. 47-65.

7. Gray, W.R.; Uddstrom, M.J.; Larsen, H.R. Radar surface rainfall estimates using a typical shape function approach to correct for the variations in the vertical profile of reflectivity. Int. J. Remote Sens. 2002, 23, 2489-2504. [CrossRef]

8. Gourley, J.J.; Calvert, C.M. Automated detection of the bright band using WSR-88D data. Weather Forecast. 2003, 18, 585-598. [CrossRef]

9. Rico-Ramirez, M.A.; Cluckie, I.D. Bright-band detection from radar vertical reflectivity profiles. Int. J. Remote Sens. 2007, 28, 4013-4025. [CrossRef]

10. Zhang, J.; Langston, C.; Howard, K. Bright band identification based on vertical profiles of reflectivity from the WSR-88D. J. Atmos. Ocean. Technol. 2008, 25, 1859-1872. [CrossRef]

11. Klaassen, W. Radar observations and simulations of the melting layer of precipitation. J. Atmos. Sci. 1988, 45, 3741-3753. [CrossRef]

12. White, A.B.; Gottas, D.J.; Strem, E.T.; Ralph, F.M.; Neiman, P.J. An automated bright band height detection algorithm for use with Doppler radar spectral moments. J. Atmos. Ocean. Technol. 2002, 19, 687-697. [CrossRef]

13. Ryzhkov, A.; Zrnić, D. Discrimination between rain and snow with a polarimetric radar. J. Appl. Meteor. 1998, 37, 1228-1440. [CrossRef]

14. Brandes, E.; Ikeda, K. Freezing-level estimation with polarimetric radar. J. Appl. Meteorol. 2004, 43, $1541-1553$. [CrossRef] 
15. Tabary, P.; Henaff, A.; Vulpiani, G.; Parent-du-Chatelet, J.; Gourley, J. Melting layer characterization and identification with a C-band dual-polarization radar: A long term analysis. In Proceedings of the Fourth European Conference on Radar in Meteorology and Hydrology (ERAD 2006), Barcelona, Spain, 18-22 September 2006; Servei Meteorològic de Catalunya: Barcelona, Spain, 2006; pp. 17-20.

16. Giangrande, S.E.; Krause, J.M.; Ryzhkov, A.V. Automated designation of the melting layer with a polarimetric prototype of the WSR-88D radar. J. Appl. Meteor. Climatol. 2008, 47, 1354-1364. [CrossRef]

17. Islam, T.; Rico-Ramirez, M.A.; Han, D.W.; Bray, M.; Srivastava, P.K. Fuzzy logic based melting layer recognition from $3 \mathrm{GHz}$ dual polarization radar: Appraisal with NWP model and radio sounding observations. Theor. Appl. Climatol. 2013, 112, 317-338. [CrossRef]

18. Boodoo, S.; Hudak, D.; Donaldson, N.; Leduc, M. Application of dual-polarization radar melting-layer detection algorithm. J. Appl. Meteorol. Climatol. 2010, 49, 1779-1793. [CrossRef]

19. Illingworth, A.; Thompson, R. Radar bright band correction using the linear depolarisation ratio. In Proceedings of the Eighth International Symposium on Weather Radar and Hydrology, Exeter, UK, 18-21 April 2011; IAHS Publication: Wallingford, UK, 2011; Volume 351, pp. 64-68.

20. Zawadzki, I.; Szyrmer, W.; Bell, C.; Fabry, F. Modeling of the melting layer. Part III: The density effect. J. Atmos. Sci. 2005, 62, 3705-3723. [CrossRef]

21. Wolfensberger, D.; Scipion, D.; Berne, A. Detection and characterization of the melting layer based on polarimetric radar scans. Q. J. R. Meteorol. Soc. 2015, 142, 108-124. [CrossRef]

22. Kumjian, M.R.; Ryzhkov, A.V.; Reeves, H.D.; Schuur, T.J. A dual polarization radar signature of hydrometeor refreezing in winter storms. J. Appl. Meteor. Climatol. 2013, 52, 2549-2566. [CrossRef]

23. Kumjian, M.R.; Lombardo, K.A. Insights into the evolving microphysical and kinematic structure of northeastern U.S. winter storms from dual-polarization Dopper radar. Mon. Weather Rev. 2017, 145, 1033-1061. [CrossRef]

24. Ryzhkov, A.V.; Zhang, P.; Reeves, H.D.; Kumjian, M.R.; Tschallener, T.; Trömel, S.; Simmer, C. Quasi-vertical profiles-A new way to look at polarimetric radar data. J. Atmos. Ocean. Technol. 2016, 33, 551-562. [CrossRef]

25. Kim, H.L.; Jung, S.H.; Jang, K.I. Estimating rain microphysical characteristics using S-band dual-polarization radar in South Korea. J. Atmos. Ocean. Technol. 2020, 33, 551-562. [CrossRef]

26. Trömel, S.; Ryzhkov, A.V.; Hickman, B.; Muhlbauer, K.; Simmer, C. Polarimetric radar variables in the layers of melting and dendritic growth at X band-Implications for a nowcasting strategy in stratiform rain. J. Appl. Meteorol. Climatol. 2019, 58, 2497-2522. [CrossRef]

27. Griffin, E.M.; Schuur, T.J.; Ryzhkov, A.V. A polarization radar analysis of ice microphysical processes in melting layers of winter storms using S-band qusai-vertical profiles. J. Appl. Meteorol. Climatol. 2020, 59, 751-767. [CrossRef]

28. Lee, J.-E.; Jung, S.-H.; Kim, J.-S.; Jang, K. Sensitivity analysis of polarimetric observations by two different pulse lengths of dual-polarization weather radar. Atmosphere 2019, 29, 192-211, (In Korean with English abstract).

29. Kim, M.; Lee, K.; Lee, Y.H. Visibility Data Assimilation and Prediction Using an Observation Network in South Korea. Pure Appl. Geophys. 2019, 177, 1125-1141. [CrossRef]

30. Lee, G.W.; Zawadzki, I. Radar calibration by gate, disdrometer, and polarimetry: Theoretical limit caused by the variability of drop size distribution and application to fast scanning operational radar data. J. Hydrol. 2006, 328, 83-97. [CrossRef]

31. Kwon, S.; Lee, G.W.; Kim, G. Rainfall estimation from an operational S-band dual-polarization radar: Effect of radar calibration. J. Meteor. Soc. Jpn. 2015, 93, 65-79. [CrossRef]

32. Ryzhkov, A.; Zrnić, D. Radar Polarimetry for Weather Observations; Springer: Cham, Switzerland, $2019 ;$ p. 486.

33. Durden, S.L.; Kitiyakara, A.; Eastwood, I.; Tanner, A.B.; Haddad, Z.S.; Li, F.K.; Wilson, W.J. ARMAR observations of the melting layer during TOGA COARE. IEEE Trans. Geosci. Remote Sens. 1997, 35, 1453-1456. [CrossRef]

34. Khanal, A.K.; Delrieu, G.; Cazenave, F.; Boudevillain, B. Radar Remote Sensing of Precipitation in High Mountains: Detection and Characterization of Melting layer in the Grenoble Valley, French Alps. Atmosphere 2019, 10, 784. [CrossRef]

Publisher's Note: MDPI stays neutral with regard to jurisdictional claims in published maps and institutional affiliations. 